\title{
From Exposition to Adaptation: The Lived Experience of Filipino Educators Working in an International School Setting, A Phenomenology
}

\author{
Julius A. Reyes, Ed.D. ${ }^{1}$, Haroun Al-Rashad D. Sangcopan ${ }^{1}$, Nathaniel P. Dado ${ }^{1}$, Katrina Alyson O. Flores ${ }^{1}$, Julien Danielle J. \\ Diokno $^{1}$, Maria Donna Melissa L. Lu ${ }^{1}$, Lloyd Hanz C. Yap ${ }^{1}$, Jana Elaine B. Hermoso ${ }^{1}$, Mark Francis J. Ison ${ }^{1}$ \\ ${ }^{1}$ Philippine School Doha, Doha Qatar \\ ${ }^{2}$ Research Development, Accreditation and Publication Office, PSD, Doha, Qatar \\ ${ }^{3}$ Research Capstone Project, PSD, Doha, Qatar
}

\begin{abstract}
Background: An OFW is defined as a Filipino citizen who is living and working in another country. The researchers interviewed several Filipino educators working in a different setting, such as international schools wherein the population of the students is mainly composed of different nationalities. Method: A phenomenological research design was done in this qualitative study to understand the adapting skills of Filipino educators in an international setting, relative to the central question: "What are the different work practices and challenges faced by Filipino Educators in Qatar who are employed in an international school?". Findings: The study revolved around the different behaviors that the Filipino educators encountered while working in a multicultural classroom. The study revealed the different coping mechanisms that Filipino educators had to use for them to adjust to the work environment, which includes not only problems with the students but also problems encountered with co-workers and parents of the students with different nationalities. Conclusion: The challenges that Filipino educators face influenced their capability to adjust to their new life. Recommendations: To fill the gap of this study, the paper suggest to have a much more specific questions such as job satisfaction and future intentions of the Filipino educators.
\end{abstract}

Keywords:- Filipino Educators, International School, Lived Experiences, Adaptation, Philippine School Doha.

\section{INTRODUCTION}

Overseas Filipino Workers (OFWs) have already been considered the new heroes of the land [1]. With these prodigious mindsets on Overseas Filipino workers, people tend to forget the unpleasant side of their condition abroad. Having an abundant and increasing number of Overseas Filipino Workers (OFWs) working abroad comes with various challenges being faced in their foreign workplaces daily. Working in a foreign setting can either have an affirmative or negative impact on these OFWs depending on their adaptation to it. Such benefits in working in a foreign setting include: encouraging their students to have global perspective about the importance of global vision, can motivate their students with new curriculum and encourage success by implementing new teaching strategies, their teaching quality improves, and they can teach diverse groups more successfully and their classroom management will be much better [2]. However, disadvantages and oppressions are inevitable [3]. Economic differences between countries are perceptible resulting in unequal life opportunities with the migrant workers' place of origin and racial identity [3]. This study, therefore, aims to unearth the lived experiences of these OFWs along with the adversities and the adaptations accompanied to it.

This study particularly focuses on the lived experiences of Filipino educators working in a foreign setting in Qatar, which aims to tackle various aspects they are facing. Filipino educators encountered some personal and professional challenges of their own [4]. School dynamics are often different from each other due to inconsistencies in staffing that would make it a challenge to establish a cohesive environment encouraging members to remain [4]. Working with educators of varied cultural background helped the Filipino educators to understand what is happening outside the Philippines [5]. Through the use of a phenomenological approach, the researchers are able to accumulate in-depth experiences of selected respondents that fit the description. These responses paved the way for the researchers to extract the results needed to apprehend and give meaning to the lived experiences of Filipino educators working in an international school setting. With these results, the study can enlighten and prepare upcoming potential Filipino educators who are expected to encounter similar challenges.

The study explores three main themes that discusses about the challenges faced by the Filipino educators and how they surpassed them. International school is an increasingly prominent sector of education serving students and staff of different nationalities worldwide [6]. International schools are usually free of the limitations placed on local schools to teach local heritage and prepare students of local citizenship, and naturally more globally oriented [7]. Due to the gradually increasing number of international schools being established globally, numerous job opportunities emerge. Educators of various nationalities employed in international schools have different perceptions of working in a multicultural 
environment. Migration is where there is a sense of adventure and is all tied up to having more opportunities and options and would result in moving abroad rather than staying in the country [8]. International School setup may vary as to how globally oriented it is nevertheless due to the increasing number of international schools being established the number of job opportunities also increase.

Every challenge that Filipino educators face may be a positive or a negative impact on them. This new experience challenges the individual to adjust and unlearn ways they originally know and adapt to their new surroundings [9]. Filipino Educators may feel homesick, new and at random times may be discriminated for being a Filipino. Working in a foreign setting requires an individual to become adaptive in navigating an unfamiliar environment and diverse culture, individuals try to fit in with the host culture and adjust him/herself according to maintain a suitable relationship and achieve social interaction [10]. Despite all the challenges that Filipino Educators have faced and will face, these challenges are perceived as a way for them to easily adapt to their new surroundings. Homesickness and being discriminated are the factors that are accepted prior to moving to a foreign setting, yet, these factors indicate how adaptive a person can be especially to those individuals who are trying to navigate an unfamiliar environment and a diverse culture. Up to this day, Filipinos continue to form organizations that help advance the welfare of Filipinos [11]. Many of these organizations help to maintain social and economic ties to the Philippines, mainly to regional hometowns; most of these organization promote Philippine Culture through a range of social and cultural activities to keep Filipinos from their cultural background [11]. Through these organizations, Filipino Educators derive social, cultural, and emotional support.

\section{METHOD}

\subsection{Research Design}

This study was executed through the use of qualitative research design. A qualitative approach is suitable for this study for it interprets and makes sense of an individual's experiences [12]. A specific type of qualitative research design, a phenomenological approach, is used to gather accurate data needed for this study. The central aspect of this research is to understand the essence of the experience that respondents share within a common ground. The researchers aim to analyze and give meaning to the life experiences of a phenomenon experienced by Overseas Filipino Workers (OFWs) working in foreign settings in Qatar [12].

\subsection{Research Locus and Sample}

This study was conducted at Philippine School Doha (PSD), it was founded in October 1992 and is a leading education institution in the State of Qatar. PSD has always been recognized for its international and national accomplishments. The institution has always been recognized as an outstanding Philippine school in the Middle East. PSD was selected due to the availability of the researchers' adviser, Dr. Julius A. Reyes to assist and guide the researchers throughout the development of the study.

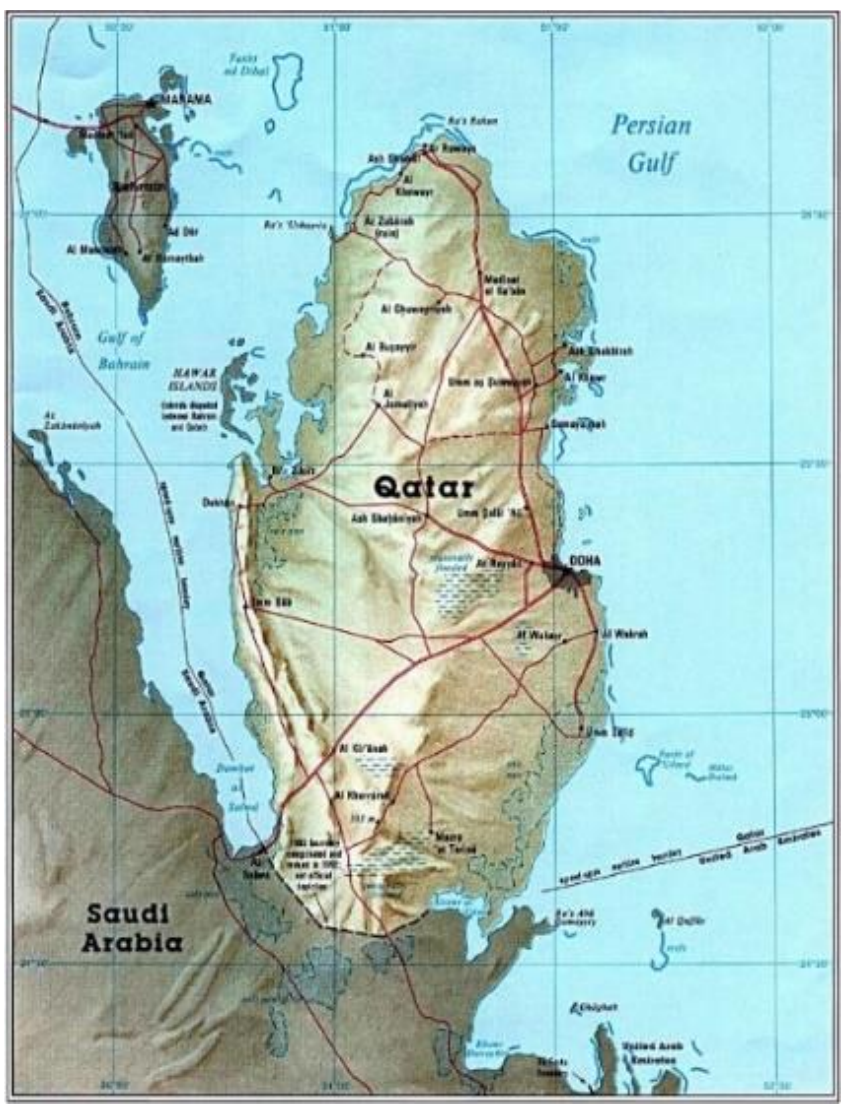

Figure 1: Location of State of Qatar cc: Google Images

The participants that were selected for this study were Filipino educators who are currently working in an International school in the State of Qatar and who have lived in Qatar for at least five years. The researchers made use of purposive sampling to select the seven respondents that would partake in the study. This involves identifying and selecting individuals or groups of individuals that are exceptionally knowledgeable about or experienced with a phenomenon of interest [13]. The participants were chosen considering the fact they are residing in Qatar and working in an International school setting in Qatar.

\subsection{Data Collection and Ethical Consideration}

The researchers utilized the robotfoto and conducted a semi-structured interview in gathering the necessary data for the study.

The participants were given copies of the robotfoto [14]. To aid the researchers with the participants' demographic sketch needed, namely, gender, civil status, educational attainment, occupation, and length of stay in Qatar. A twentynine item semi-structured interview was directed, which enabled the researchers to divulge the participant's personal experiences and certain events pertinent to an international context.

Interview proper is a critical component of many types of research, and it is often conducted as one of many diverse methods to collect rich individual data and storytelling evidence. It is done by recruiting participants, establishing a recording method, developing questions, interviewing participants, and conducting further research [15]. The 
researchers are determining respondents through the researchers' hope to learn from talking and identifying the people that will provide the researchers with the most productive data and information possible. The scope of interviewing can vary widely, determining a sufficient number of people to interview in advance. Whenever sensitive questions are going to be asked, the researchers are required to inform the respondents in advance; the researchers must obtain IRB (institutional review board) approval when interviewing with sensitive questions or topics [15]. With the help of recording through the researchers' digital technology, the data was gathered and used for further research. Before doing so, the researchers asked permission by giving consent letters to the participants and waited for the participants' approval.

\section{Data Analysis}

The researchers have followed an inductive approach in developing themes [16]. The researchers have comprehensively analyzed the data gathered: (1) listening to the audio recordings and understanding the respondents perception about the topic; (2) doing the emic transcription through transcribing the data gathered verbatim; (3) modify the emic transcription to etic transcription which is the understanding of the researchers based on the responses and body movements of the participants; (4) organizing constructed meaning into categories, placing thought units, and cluster themes through dendrogram to show the similarities of the gathered data; (5) formulating a simulacrum as a visual representation of the findings.

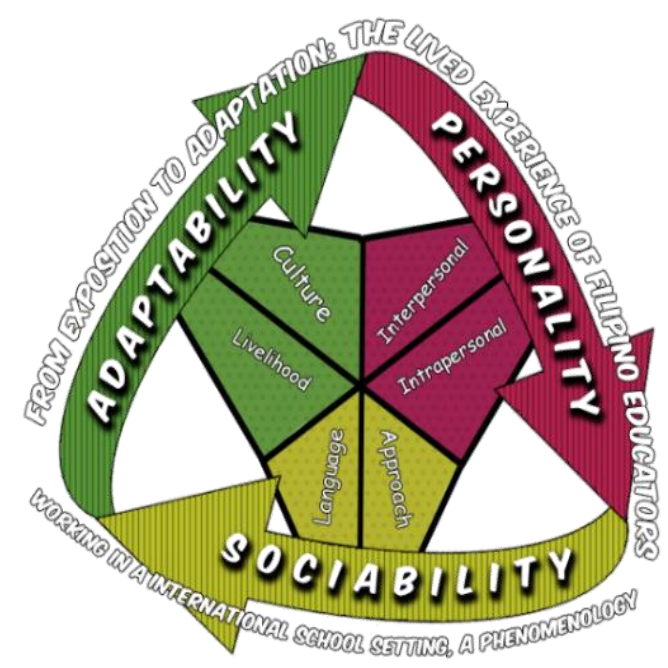

Figure 2: Simulacrum. The challenges faced by Experienced Filipino Educators Working in an International School Setting

\section{FINDINGS}

This phenomenological study describes the lived experiences of Filipino Educators working in an international school setting, specifically those who have experienced working overseas and, in the Philippines, relative to the central question: "What are the different work practices and challenges faced by Filipino Educators in Qatar who are employed in an international school?'

Figure 2 shows the simulacrum focused on three major themes: Adaptability, Personality, and Sociability. These themes portray the challenges that Filipino educators face daily in their work lives overseas, and how they cope with the struggles that they face.

\section{A. Sociability}

Sociability is the ability of one person to socialize with others in their workplace, school, and community. Everyone has a distinct way and reasons to socialize with others. Being able to socialize, is an advantageous skill to someone who is introduced to a new setting or environment. The ability to swiftly socialize with others allows one to gain new friends and adapt when introduced to a new environment or new ways of life.

Yet even if a person has sufficient skill in socializing, facing a few bumps here and there is inevitable. They will still face challenges along the way that would hinder them to socialize with others. These challenges can be surpassed by trying different methods, and techniques. One must not be surprised when they face challenges that are beyond what they can cope with.

Some of the few challenges that one may face when socializing with people of varied cultural backgrounds are the difference in language and the approach to bond with them. For the sole purpose of the study, sociability is further divided into two subthemes: Language and Approach.

\section{Language}

Language refers to the language barriers the respondents faced and how they adjusted to surpass such challenges. The key to a positive and lively workplace is communication, it enables people to understand each other and promotes adeptness. When such barriers are present for one to communicate with one another it hinders a positive communication and may promote misunderstanding to each other.

When working in an international school setting in the middle east, it is a given that one would find it hard to work with the locals. The respondents found it hard to adapt to their new environment, to communicate with their co-workers, and to understand their co-workers. It was not a walk in the park to adjust to a place where you barely know their language; speaking in English would not even solve their problem since most of the locals are not even fluent in the English language.

"Language, that's the first thing, because I don't speak Arabic. I know a few things or words, but I struggle with most of the words. (R3)"

"Though, not just only in school or teaching settings, most OFWs are experiencing these struggles regarding this language barrier with the different nationalities. The locals, most of them are not able to speak fluent English. That's one of the problems I got. (R6)", 
"Their language. Because they are Arabic, they would not understand if you speak straight English. (R7)"

Having English as their second language, they thought that it would be easier to work in an international school even if your co-workers are Europeans, Americans, or from countries that have English as their first language. Yet, that was not the case; even if they have co-workers from the mentioned places, they still faced challenges due to the variation of accents. Different accents and different vocabularies from different places are what hinders them from communicating with them and simply asking them to repeat and to say slowly, simply did the trick.

"Actually, it's really challenging at the first-year cause some of them have strong accents. You can't understand what they are saying. Actually, not only us, Filipino educators, even the other nationalities, especially the British staff. When they talk, it's hard to understand them. When these happen, sometimes I just ask them to repeat what they say so that it's easier to understand and communicate with them. (R6)"

"Language is one thing, language barriers because we are used to American English and I'm working in a British school where they impose British English. If you speak and sound like their language, they'll like you. (R3)"

"I talked about language that's one thing, the English language is one barrier that separates American English from the British English and the Filipino English, we as Filipinos, we have our regional accents, so we are not that fluent who could have a conversation with these people because these people feel like they are superior, mightier or much better than us. I know when it comes to vocabulary, they are good with it because that's their first language but when it comes to us, it becomes a challenge. (R3)"

Yet, one must still try to surpass a challenge, and that is exactly what they did. Simply asking their co-worker to repeat what they say made it easier for them to convey to their co-workers that their manner of speaking is too fast for them to understand and to their co-workers who do not have English as their first language cutting down words that there are familiar with is what worked with them.

"In giving instructions, because not all of them came from one city or country, some of them are Scot, Italian, French, and South African, so they have different ways of pronouncing words and initiating them, you have to look at their face and how they open their mouth or else you won't be able to understand what they are talking about. There's one incident where in a Scottish teacher gave instructions to all of us and he was blabbering words, he was giving instructions and we didn't understand. After his instructions were given, we approached him in his room and we asked him slowly "sir could you please say your instructions again? Like in this manner", so with that gesture he found out that he was talking to fast. (R3)"
"The language barrier. Sometimes, if you speak straight English, they are not able to understand so you need to speak broken English for them to understand you. (R7)",

"In communicating with them, there are things that what you say is totally different from what you mean. What I do is I repeat myself and ask for clarification because I don't want to have miscommunication and misinformation. (R1)",

"Yes I have trouble communicating with them since they all have different accents and sometimes I need to ask them the same question again and again for me to comprehend what they are saying (R5)",

"Yeah, it's the same thing with the accent when they are talking. (R6)"

However, when it comes to their student's and parents table do turn; for them to communicate with them effectively. They believe that patience is the key to allow students to understand on their own and they also use all the resources they have at their disposal to have communication with their students, such as sign languages, body languages, placards, Arabic translators, etc.

"I, as an ESL teacher, patience is the key for us to understand each other despite the fact that they don't understand the English language. (R2)"

"It's difficult because they speak Arabic and I don't, but when it comes to the English language it's easier. Most of my students are in learning support, so there are learning difficulties and it's hard to deal with it especially with the ones who are diagnosed with mild symptoms. You have to use all the resources you have in the room and all the things that you've learned when you were still a student. You have to transfer the learning the best way you can. (R3)"

"The most challenging part is to teach students of different nationalities especially those who do not understand English at all. (R2)"

"It's the same issue regarding the language barrier, especially the Arabic students. In year two, they are having problems with English, with Arabic being their mother tongue. It's really challenging to teach using the English language with them. (R6)"

"This was also one challenge that I faced when I was just starting out since most students do not speak English, I needed to repeat my words again and again until they understood. (R5)"

"Basically, we're using the basic, easiest English words that they can comprehend for them to understand the lesson. Unlike in the Philippine school, where you can use straight, proper English and the students can understand it. In contrast, you have to use the easiest, simplest terms for the Arabic students to understand the lesson. (R6)" 
"Yes, actually first of our students don't understand English, and through the use of instructional aids and training from the school, we were able to teach these kinds of children. (R2)"

"Yes. Not all Arabic students speak purely in Arabic, most of them can speak English but we still need to simplify most English words that we are using to make lessons clear with them. (R6)"

"Yes, it is there all the time since I told you I'm working with students of different nationalities. For example, I have a student who is from Iraq he does not speak English. I started with him since august and I feel he is not trying to learn so I struggle with him. Every time he always speaks to me in Arabic and I have my other students or co-teachers translate for me. Whenever I spoke with his parents, they also do not know English so it is really hard for me to communicate with them. (R5)"

"Like what I said from before, you really need to use body language, gestures and most especially, pictures. (R7)"

It is not always about body language and sign language for them to be able to communicate with their students and teachers. For the teachers, Parents' Day is one of the challenging days of being a teacher in a foreign school, communicating with the parents of their students, and making sure that they understand their children's progress. In doing so, they ask help from their co-workers who are fluent in Arabic sometimes their students to translate everything to their parents so that they'll understand. Yet, the problem from asking help from students is that you will never know if they said the right thing to their parents.

"When the parents usually come to us, they somehow try to speak to us in languages where we both understand each other, because we use the easy words where we both understand each other. There are other words with different meaning because we are using the British language and so, we use words very carefully because it might mean the other way around or give the other meaning, we give direct instructions and we have to make sure that they understand. If they don't understand, then that's the time we get our translator and have it printed because we have to make evidences to show that we've given the instructions very carefully. (R1)"

"Yes, as I have said we have Arabic teachers who translate for us when its card giving or parents conference. There was also a sudden instance where a parent asked me about something and it was hard to communicate with her since we didn't have Arabic teachers around. (R3)"

"It's a bit challenging because of the language barrier. Sometimes I need to find a translator in order to make the message clear to make it even more challenging some of them can't use online communication to fix this problem. I needed to call them through my personal phone or set an appointment in order for us to talk about the progress and behavioral problems of the student. As well as the students who are gifted or talented their parents have a high standard for them and equally high expectations from me so I dealt with them properly by communicating with them. (R4)"

"In dealing with the language barrier as I told you, I have some co-teachers who can speak Arabic so I can have a meeting with the parent with the help of my co-teacher who translates for us so it was easy. (R5)"

\section{Approach}

Approach refers to the physical barriers that educators face when they socialize with their co-workers and students of varied cultural backgrounds. These are challenges that hinder them to adjust to their new environment / new life. When they get called or noticed because of these barriers in does not always boast their confidence, rather, it shows their insecurities about their culture and themselves.

When it comes to their students, the educators were struggling with how they behaved in the classrooms and towards the people around them. It came as a shock to them since they are used to students that would usually say "po" or "opo" to them. They find it difficult to adjust to students that are hyperactive in school who act the total opposite of the students they are used to handle. To deal with misbehaviors of such students they set rules to show to the students that they must respect people around them specially their parents and teachers. For them to make sure that their students are learning, they set standards for them to know and assess if their students are progressing.

"The struggles I have here basically is the behavior of the kids in a classroom setup. The kids are unlike Asian kids or unlike our country men, the kids are so active, they are opposite of the kids we have. (R1)"

"I talk to them in a nice way and trying to understand why they are acting in that kind of behavior. (R2)"

"We have "good to be green" behavior policy in school, so it's very easy. I always have the yellow, red, and black cards in my pocket, so whenever I see a student misbehaving, I just take them out of my pocket let them choose. It's going to be a big problem because their parents would be called if they get a black card and if they are fighting, they'll get a red card and it's a yellow card if it's just a warning, if I get 2 warnings, it's going to be red. It's easy unlike other Arabic schools here, it's terrible, their voices are louder than yours. It happened in our school one time when there's this one student who shouted a negative thing about Qataris, it was like a war because he was in a middle of the football field and the rest of the locals are surrounding him that time and poking fingers at him because he said something bad about the Emir. From that day until the end of the school year, he wasn't able to have his break outside, he has to stay in the room or else he'll be bullied. It was in the middle of the field, he was like crumbling to the ground and the rest were kicking at him, but nobody got punished just him. It was his fault anyway. (R3)" 
"Our school implements a behavioral management system using a website called class dojo where I can give students positive or negative points and regular communication with the parents can also improve their behavior in doing so can also establish a good relationship with the parent and the student. (R4)"

"In our school we implement a strike policy where each time a student breaks a rule, they get one strike and when they get three strikes, they get detention during break time since I'm dealing with year one students it is very easy for me to impose this policy. If it is consistent this policy is very effective. Besides this policy we are also using the class dojo where I can give them positive and negative points and I give them a specific number of points they must accumulate to get a reward and this motivates them towards a positive behavior. (R5)"

"We have different behavior policies for these misbehaving students and it always works without a problem. (R6)"

"What is important is to get the attention of the children, especially the little ones. Talk to them and warn them not to do this misconduct ever again. (R7)

"Students are categorized as low, medium and high ability and depending on this I prepare whatever is necessary and take into account each of their particular needs. For example, I give them different activities suited for them. (R4)"

When it comes to their students' parents, they are indeed lucky that they do not have to deal with such challenges at first hand. They directly approach this to their managers so that they will be the ones to deal with their parents. When the educators are given a chance to talk to the parents of their students, they do their best to make sure that parents understand their standards to help their children to have positive progress, yet, it is inevitable for parents to react when they have a concern about their child/ren and the educators have then realized that it is better to listen and understand the parents rather than back to them.

"Dealing with the parents is a little challenging however when I communicated with them regularly it made it easy. I oriented them and told them what my expectations were in order to establish a good relationship. (R4)"

"I was specifically clear with communicating with them about my expectations, expectation with the students and how to achieve those expectations. (R4)"

"I just listen and respect whatever they say. Because there's no point if you argue with them. (R2)"

"In our school, we do suctions if they commit mistakes or if they've done bad actions. If a major thing happens to the kids, we escalate it to the manager. (R3)"

"When I encounter difficult parents, I talk to my manager and my manager can help in order to establish a rapport or a good communication with them. (R4)"
"Sometimes I just ignore them to make them feel that what they did was wrong. I had parents who always complained about me. For example, the parents say I forgot to send the book or forgot to send an assessment. I just ignored them and I sent her messages every day on Dojo as a reminder of the things needed. Apparently, she is okay with me now since she stopped complaining (R5)",

"The parents' main concern is their child's performance, so when we have some issues regarding their behaviors, we just send them to the principal's office and leave it to them to deal with their personal matters concerning their children. (R6)"

"one negative thing I can think of is I cannot express my cultural values unlike in Filipino schools. I think that Filipino educators dealing with Filipino students is the ideal scenario than dealing with these students who have a behavioral problem. (R4)"

One of the problems with teaching in a foreign setting, not only do the educators have to adjust to their students, but they also have to adapt to their co-workers. To do so, they make sure that they learn the cultures of those they work with to make sure that they do not cause such discrimination or that they do not offend them. It is not an easy task to do, especially they do not get the same treatment as the way they treat them, but the educators had to make do of what they had just to survive the challenges they face.

"We make sure that we learn first the things that should be considered including all matters of learning so we read and research among the things that we have to consider in front of the kids and in the classroom setting. We also make sure that we don't touch anything that would offend the kids considering that we have both different cultural, religious and all other aspects of views. (R1)"

"On my first year here, it was actually challenging. I try to adjust not just with foreign educators but also co-Filipino educators. There were Nepalis, Pakistanis and Indian staffs. It was a bit difficult to adjust because most of them prefer to be closer or work closer to their former bosses, however, I was able to cope up after what happen. (R3)"

"We all have different behaviors and as an expat we have to adjust to their behaviors. I think respect is the best key to understand each other's differences. (R2)"

"I'm the type who adjusts easily with people. I don't care if you don't like me and if you like me it is much easier. If you don't, I'll always find ways to make you like me not leading to friendship, but when it comes to being workmates, you will be able to get along with me. It doesn't take much long to adjust, for me, I find it easy to work with people as long as you are able to communicate yourself with them and they understand you, it's okay. One thing that you shouldn't forget working with foreigners, is to show and give respect that's when they'll give you back the respect you deserve. (R3)" 
"It took me a while, but you really need to adapt and bear with them even if you get irritated. (R7)" (R4)"

"I can say that it is challenging to work with them.

"It's really challenging, as I said, but we still have to work on it because you'll be spending the whole academic year with them. (R6)"

"You need to lengthen your patience with them. (R7)"

However, even if they do adjust for them. Their coworkers seem to be the ones who have problems. They are mocked, degraded, discriminated against, and treated differently because of their culture. The worst part is they experience situations that could have been handled professionally.

"They are the type of people who uplifts you and it is sad to say but these types of people won't put you down and lift you up. They are totally opposite to our fellow Filipinos and I can see that they are also honest with how they deal with other Filipinos which is a wonderful aspect of having them around. (RI)"

"When it comes to work, as far as I could remember, I've done my best in that school and I haven't experienced any mockery. (R3)"

"Working with other people with different cultural backgrounds was really hard because you have to adjust for them and it is not them who will adjust for you. (R2)"

"The food that we, Filipinos ate in the school that's one thing, but sometimes, I forget that I am in a room full of Filipinos and foreign educators and then I was speaking in our language and I was too loud, everybody that are not Filipina are thinking that we are talking behind their back because they find it rude when you speak your own language in a room full of foreigners. It's also the same thing if you are in the same situation. I was able to adjust, it is only at the beginning but I don't want to lose my job, so I have to speak the English language because it's one of the rules of our school to speak the language or else we'll be in trouble. (R3)"

They said that it is nowhere easier when you are made higher than them. They treat you no differently at all and giving tasks to them is as hard as trying to bond with them. When the situation is at its worst, they do now have a choice but to talk back to them and raise their voice just to be able to be heard.

"In dividing the workloads, because a lot of them are lazy. I'm handling 5 classes and then the rest of them went to the prayer room and to the staff room, their hiding themselves and most of the instructions were given to me and I just have to pass it to them. There was that time wherein I wrote all the things that we need to do and I circled most of them, then I haven't circled the last one for them to do. When they checked, they did all those things without realizing that I've done most of those things on the list and then that last thing actually is the most difficult thing to do. I made the list of actually similar things but they weren't able to find that out. (R3)"

"Yes, sometimes they insist what they know and all you have to do is just to follow them. (R2)"

"Yes. I talk back and oppose to what they insist so we raise voices at them. (R7)"

"It actually feels challenging because you have to adjust and you have to try your best. I'm the type of person who does her best on whatever task that are given to her, it's our raise and nicety that's going to be affected if I'm not going to do the best. Most of my co-workers now are the type who pretends to work hard when our line managers are there, but when they are gone, they'll just leave the things and leave the room untidy but nonetheless they are my friends because if I make them one of my enemies, it's going to be a problem. In a workplace with a group of Filipinos and British, they try to go to a group where they could benefit more and Filipinos are the type who are loud when they are offended or when they are hurt, so I don't want to be one of those people. I'm trying to be more friendly to them. (R3)"

\section{B. Personality}

Personality is what makes up a human being. It is how a human being reacts, behaves or thinks in given circumstances. Everyone has their own distinct personalities that create variation from one person to another. However, when put in the same situation, people have the tendency to acquire similar personalities that conforms to the norms of the given situation.

Setting foot in a whole new environment inevitably affects one's personality. Migrating to a new country comes with a different way of life from what is acquainted to. This way of life pertains to the attitudes and behaviors accustomed to the society that may be influenced by their country's beliefs, religion, or law. In layman's terms, this is their culture. Correspondingly, expatriates tend to adjust their behaviors as a way of adapting to the unaccustomed setting. To be exact, for the purpose of our study, these are the Filipino educators working in an international school setting in Qatar.

Certain workplace systems and associates are influential forces in the respondents' personality development. These educators gradually assimilate new encounters and experiences with these environmental factors, which contribute notable changes in one's career, interests, ambitions, motivators, beliefs, values, and lifestyle choices.

Personality is then further divided into two subthemes: Interpersonal and Intrapersonal personality.

\section{Interpersonal}

Interpersonal refers to how the respondents' personality is affected by the people around them. Relationships and 
interactions with other people have a way of making expatriates cope and feel more comfortable in a foreign country. These people around them create a positive impact on their personalities that steers them towards personal growth.

These relationships and interactions which are incorporated to the values or morals of the respondents helped them to adequately reach a point of clarity and acceptance about the new situation they are in. The respondents relied on the different types of relationships and interactions to face the difficult challenges they encountered. For instance, the norms of teaching in the country, teaching strategies and many more, which provided a connection in the workplace and developed an evolved mindset that deeply contributed to their mental and emotional state. A respondent stated:

"Personally, it makes my personality stronger for I have learned to deal with different people and cope with different difficulties that may come my way." (R4)

Working in an international school is an entirely different setting from what Filipino educators are used to. As former educators in a Filipino school, not only do they have to adjust to the students and colleagues of different nationalities, but they also have to adjust to the curriculum of the international school. A respondent compared the two settings:

"I have had a lot of experiences since I have worked in two different schools. I can say that first I worked in a school where most of the students are Filipino and the school that I work for now has much more students with different nationalities. I can clearly state that it is totally different." (R5)

Having these disparities between an international school and a Filipino school, Filipino educators could not possibly adapt on their own. Working with their foreign colleagues, the Filipino educators were able to learn from them and vice versa. The respondents used their foreign colleagues' positive reception of their work performance and character as a drive, which effectively elevated their own prospect of themselves as well as how they operate their commissions:

"Working with the foreign educators, I learned some teaching strategies from them as well as them learning something from us, Filipino educators. On how to deal with students, how to teach the lessons, for example. There are mutual effects between us Filipino and foreign educators." (R6)

"Yes, since they are from the UK or South Africa, they are familiar with the British curriculum which we use in our school whenever I have a problem regarding this and I just ask them and they have proved really helpful." (R5)

"It is a lifelong process. While you are working together, you will learn a lot, so I don't think it has to have, so I could learn as we go on." (R1)
"So far, we've learned something that we can apply and adapt to a Philippine school, when going back to the Philippines. I learned a lot from them." (R6)

However, working with foreign colleagues is not only limited to having positive impacts on the Filipino educators' work experience, but also to their psychological well-being as emphasized by the respondent:

"When it comes to working with foreign educators, it's not just your mental aspect that benefited but it's also your moral and emotional aspect, because when you mingle with them it is totally a different thing, they uplift you and make you feel like you are one of them, but if you are so proud of yourself, they will turn their backs on you and let you lead your way, but if you are with them, they will raise you up and make you feel that you are great. That's one thing that I like about them compared to the co-Filipino educators when I was in the Philippines, you will learn a lot of positive adjectives if you're working so hard, but if you're too lazy, they won't even call you." (R3)

In creating an easily adaptable environment for educators of different nationalities, international schools offer certain programs that will assist employees in working with them. As two respondents said:

"With the help of our managers, training and orientations about the school, their policies and their curriculum were held before starting the school year." (R6)

"Actually, our school is conducting some professional development training for the teaching staff to update or give the modernized way on how to teach the students. Like when we are doing some internal and external development. I think I can apply that. This one, even in our Philippine curriculum, will work." (R6)

Homesickness is fairly common to overseas Filipino workers; it is a baggage that comes with working abroad. These Filipino workers have developed various coping mechanisms in dealing with homesickness in which relationships with the people around them plays a significant role. A respondent described:

"We are thankful for technology because we get to chat with our family and call them on viber or other modes of communication. The kids here help us because there are kids who are really sweet and they lessen your homesickness as well as the school administration, they are also supportive to the teachers and our colleagues, there are several Filipino teachers around and we get to talk and hang out a bit to ease the sickness." (R1)

To be specific, the respondents claimed that being around and spending time with other people such as their friends and families in Qatar lessens the feeling of homesickness:

"I go out with my family and our friends here in Qatar.” (R7) 


\section{"I bond with my friends to make myself busy." (R4)}

"Yes, going out or hanging out with my friends helped me through my home sickness even if it's just for a short time." (R5)

"I think the best thing to do is to go outside when feeling homesick. Don't stay alone. Go out with friends, spend time with them outside." (R6)

With these said, the respondents significantly integrated workplace ethics, practices, and encounters, acquired from consociates, to their respective dispositions so as to execute their duties more efficiently, furthermore, improve their personal facets. These environmental factors succoured in reassuring and gratifying the overseas Filipino workers a sense of normality albeit undergoing foreign circumstances.

\section{Intrapersonal}

Intrapersonal, as from the prefix 'intra-', comes from within. It is how the respondents think or perceive certain situations; it is what goes through minds. Basically, this is their mindset. When faced with circumstances, one decides on how to take them personally: either positively or negatively. As from the responses, the Filipino educators often dealt with these circumstances by thinking of them as motivators instead of discouragements. With this mindset, it pushes them to continue working despite hindrances.

Working in an unknown environment gives way for Filipino educators to benefit from the experience by continuously growing in uncertain situations and learning throughout the journey. Overall, an improvement on the respondents' character was inevitable. With this, a strong feeling of achievement and fulfillment occurs as expressed by a respondent:

"There's a bit of fulfillment and achievement at the same time I was able to learn because it has a lot of things like work wise socially and at the same time it has helped me build myself as an educator because it is totally different from what we have back home in the Philippines." (R1)

However, it may not be the same view for some Filipino educators. Working in a new environment, one may look for certain qualities that they are accustomed to. These certain qualities may have created a void within the Filipino educators that hinders them to reaching acceptance in the new setting. As a respondent stated:

"Honestly, still looking for the same type of school, workplace, and teaching job in The Philippines." (R6)

It is natural to have different challenges tailored to certain workplaces and it depends on the workers to decide on how to face them personally. Acquiring a mindset that generates a careful analysis on ways to adapt and makes the most of the situation at hand creates an outlook that sees challenges as a path to personal development. As affirmed by the respondents:
"I needed to be a strong person and apply different strategies in order to adapt to the culture and the different procedures of the school." (R4)

"I just take all the challenges in a positive way." (R2)

"I turned it into a positivity tribe because we don't get the chance to be with them for a long time, as a result, we don't know if we would still be here and so, we make the most out of it and learn from them." (R1)

"I react to challenges by seeing it as an opportunity to become stronger by keeping calm, finding time to meditate and adapt with different challenges." (R4)

\section{"I react by simply challenging myself." (R5)}

"It is actually challenging. I have to adjust and work it out." (R1)

Filipino educators have shown great respect when working and interacting with colleagues of different nationalities. They remain professional in terms of learning from them and prevent their pride from dominating them. With this attitude, the Filipino educators were able to grow, not only in the workplace, but also as an individual. The respondents affirmed:

"We will learn a lot from them which is the first thing I put in mind and I don't put myself over them. Their education is totally different from ours and so, we learn from them and I'm open about it. I make sure to learn and I don't see any jealousy in it." (RI)

"It depends on you whether you adapt to them so they would adapt to you." (R7)

"It was hard at first, but as time passes by, I learned to accept the reality and it feels great to think that they made me stronger when it comes to decisions in life." (R2)

Correspondingly, Filipino educators get highly motivated when having foreign colleagues recognize their hard work. It fulfils their national pride and boosts their enthusiasm to continue improving their performance at their workplace. As emphasized by the respondents:

"It feels good anyway, as a Filipino I can work with other nationalities and showcase our culture and how Filipinos work hard and it actually feels amazing because they appreciate it a lot when they see how hardworking we are." (R5)

"We are having this Teachers of the Month and I was actually the Teacher of the Month last November and I got a certificate and cash prize from our manager. I'm proud; out of all the Filipino educators, I was chosen as one of the best teachers of the month. It's a voting process so it means to me that the other teachers, foreign educators appreciate my efforts as a Filipino teacher." (R6) 
The salary is a significant factor that prompts Filipino workers to work abroad. The Filipino educators noticed a drastic difference in salaries in international schools as compared to former Filipino schools they have worked for. With this in mind, it keeps them going knowing that their hard work will be paid off and they will be able to provide sufficient support to their families. The respondents shared:

"The benefit is the salary, and the salary matters most because since I am paid more, I am more motivated for this can help me provide for my family." (R4)

"Aside from the "star of the week" and the" star of the month" certificates that I got, there's nothing else. It's just the difference in what I'm earning now and with what I've earned way back in the Philippines that helps me go on with life. It is my family that I'm working for, I am working for our future, which is making me work efficiently or else I will lose my job if I will be too lazy. After 5 years of being so loyal to that school, I haven't received any raise. I think I will leave if they are not going to give me that benefit but so far, it's okay compared to the master teachers in the Philippines, I earn much higher than what may be." (R3)

"For example in our school pays more than Filipino schools so this motivates me to work harder and one benefit we have is the employee of the month where in the manager appreciates your work and it really boosts your self-esteem and in some way you will be able to forget the discrimination when they see that Filipino educators work really hard and effectively." (R4)

"I don't have a specific benefit in mind however the last time was in march this year when I got the teacher of the month and they gave me an incentive." (R5)

Working in international schools, as described by our respondents, seem to be less stressful in terms of the workload and working days. The respondents made a comparison:

"No, I don't think so, if teaching is your passion and you have the compassion to teach, I don't think it's going to make any difference. It's just that you know you'll feel envious or jealous because they're earning more than what you deserve, well that's life, you'll just have to adjust to whatever is given to you as long as they still pay you what you deserve. Another benefit that they give you is lesser workloads compared to the workloads that I had when I was in the Philippines. It's much better here. I work hard every day, I don't care about the workloads that I have because I got used to working overtime so I don't really care when I have to take work home with me because it's much better than to go home with nothing because I'm leaving alone and it's boring if you just sleep and watch movies. It's going to be more depressing if you are not working at all." (R3)

"Compared to the other workers in the other centers of the society, educators get 2 days off, we can go home early, we have so many holidays, we have short term breaks and aside from that, we get a chance to get other jobs which helps us a lot." (R1)

Being able to work in these international schools is enough for Filipino educators to keep motivated. Having this opportunity to work abroad is a huge accomplishment for Filipino educators as the respondents affirmed:

"Yes. Sometimes I think that way however whenever I look back to my life four years ago I can say that my life now is better and that's how I comfort myself and just do my job to the best of my abilities." (R5)

"For me, I don't see these differences in a negative way. I just hold myself; I went here in Qatar to work for my family and as long as I have a job it's already a big blessing from God.” (R2)

Discrimination is a common aspect in an international setting. Filipino educators have experienced a discrepancy in the treatment between them and their foreign colleagues. However, instead of seeing this as a disadvantage that hinders the respondent, a sense of drive arises, to prove that Filipinos could stand at the same platform or perform at the same level as other nationalities. The respondents said:

"We can't deny the fact that some of these people look down on us. I feel discriminated against by them however since we have the same work I just challenge myself to prove to them that Filipinos can also do the same things they can." (R5)

"Yes, but I don't feel that way I just take it as a challenge." (R5)

Filipino educators have the toughest will to prove themselves by considering difficult instances as roots of selfdevelopment and establishment of individuality in their work premises. This progressively improves themselves by learning from past experiences and setting realistic, critical standards for them to meet and eventually exceed. They are intent on facing challenges with a calm and pragmatic approach pertinent to their persona as they continue to venture on an unfamiliar setting. The respondents stated:

"I'm able to improve myself professionally and I'm also challenged to do better things than what I learned compared to the previous school. If your goal after your studies is just being able to work and earn, that's going to be a lousy life but if you aim higher then you will be able to improve yourself. You won't just be effective in your work, you're also efficient to improve yourself." (R3)

"First I needed to live up to their expectations not only with my co-worker's expectations but particularly with the managers expectations. If they need something done I do it as efficiently and effectively as possible." (R4)

Intrapersonal personality also touches on the emotional aspect of the respondents. This refers to how they feel in given conditions. Homesickness is a huge factor that takes a toll on the respondents' intrapersonal personality. Being 
sentimental when away from family for quite some time is inevitable for Filipino workers abroad.

A typical coping mechanism for homesickness is doing habits that one does in their home country. In a way, it evokes the feeling of familiarity. These habits could be celebrating certain events, eating native foods, and many more. A respondent said:

"Work, and then at the end of the month if you earn money it is totally different from what I earn in the Philippines which makes me feel less homesick and all of my friends that are here. The latest place or latest factor that helps me feel less homesick is the library because I used to go to the national bookstore when I was in the Philippines and to all the bookstores in our city. When QNL opened, I chose to live near the library because it's easier to go there." (R3)

The feeling of homesickness can be triggered by different situations in different forms. One of which is during special occasions that are personal. These personal occasions give a feeling of familiarity that one may find lost. Eventually, a development in character arises that creates a coping mechanism for this homesickness. A respondent shared:

"It is just during occasions, a minute or maybe 5 minutes. It usually happens when it's my mom's or dad's death anniversary. The last time I cried was last April, when our second mom died that I had to go home and when I came back here, I felt like something is missing because I got used to going back home and chatting with her and now it's different because I don't get to see or have a video call with her anymore. I just watch movies to help me fix my emotions." (R3)

The usual occurrence of homesickness to the Filipino educators happens when they are alone. A factor that helps the respondents in overcoming homesickness is exhaustion due to work, which serves as a distraction, and overall creates a developed work ethic. The respondents affirmed:

"Perhaps whenever we are tired, we can't really say when we feel homesick, sometimes it just happens, especially when you're alone." (R6)

"In general, I feel homesick when I am at home however when I am at work, I keep myself busy and it feels normal." (R4)

\section{“I just keep myself busy.” (R2)}

"While at work all I do is keep myself busy for me not to feel homesick.” (R4)

"I think I don't feel home sick while at work because I'm preoccupied so I don't feel it until I get home." (R5)

Having the Filipino educators busy at work disregards their feeling of homesickness that may possibly affect their performance as claimed by a respondent:
"I tend to overcome it and I don't think about it. I set it all aside for a while and I don't let it affect me because eventually it will affect your work and performance. I will set it aside and then after my work, I will deal with it." (R1)

However, one respondent has claimed that they do not experience homesickness at their workplace:

"I don't actually feel homesick when I'm at work because I'm having a video call with my siblings by putting my phone in the corner where my direct line manager doesn't see me." (R3)

The sight of fellow Filipinos with their family in Qatar is emotionally hard for some respondents as one tends to compare certain situations to the situation of others. The respondents have no choice but to develop acceptance in order to progress and continue working. The respondents expressed their feelings:

"Seeing them you will get emotional and you will get to compare yourself because they are able to share their family around but we have to have acceptance in order for us to work and to move on." (RI)

"I feel sad because I also want my family here with me." (R4)

"I envied them and wished my family were also here." (R5)

"Eat with them, join them, or turn my back at them or else it will make me cry. It happened to me during one of the winter celebrations at PSD, I'm alone and the rest of them are with their family, it's sad but I made this choice so I have to stick with it." (R3)

To some of our respondents, however, encountering fellow Filipino families in Qatar creates an uplifting aura. Instead of feeling disheartened, they become inspired and a sense of national pride arises as two of the respondents said:

"They become my inspiration to strive more because it was also my dream to be with my family here." (R2)

"I feel happy because the number of fellow Filipinos residing here in Qatar are increasing. " (R7)

Filipino workers who have their families in Qatar experience homesickness in a different sense than those who are on their own. Having their families in Qatar creates a comfortable environment for them that resembles being in their home country. This lessens, or possibly dismisses, the feeling of homesickness. As a respondent said:

"It depends, because my family is here with me. Others lack the presence of their family here and that is a different situation." (R7) 


\section{Adaptability}

Adaptation is a prime factor when it comes to survival in a different environment. It is most useful when individuals find themselves in an unfamiliar setting that they have never encountered. Knowing how to adapt to a new setting increases individuals' chances of a peaceful and well-adjusted life within the foreign community. Failing, on the other hand, leads to a variety of struggles related to the difficulty of transitioning from a familiar niche to a new one.

\section{Culture}

In the case of the respondents, adjustment to culture and livelihood had been one of the hardest challenges they needed to face. It is not easy for people to adjust to a different environment, especially if they came from a country like the Philippines. Moving to a new country such as Qatar can prove to be a difficult challenge as it meant that they had to adjust to the stricter and more conservative laws of the Islamic country. Moreover, they had to adjust to the differences in their work environments and the behavior of their co-workers in the setting. Learning how to properly communicate and relate is needed in order to achieve this. The respondents expressed their thoughts in this learning process:

"There would be differences, of course, in their culture and traditions, especially how I would be able to learn their language." (R7)

"Yes, you can learn a lot from them, especially with their language, culture, and their beliefs. And you would learn how to eat their delicacies." (R7)

Working in a new country leads to a lot of new elements introduced into one's life. And being able to properly accustom oneself to their work environment can prove to be beneficial. However, Filipino educators find themselves needing to face cultures and behaviors in their new host country different from their own. Some of them took the time to get well-adjusted, while some of them relatively had eased in adjusting. The respondents shared how they adapted to these elements:

"You need to know the differences between your culture compared to them." (R7)

"By following and respecting their culture and traditions." (R2)

"It took me months to adjust to their behavior, culture as well as their expectation from me." (R4)

"We have rules and regulations in school and we have to abide those when it comes to religion, language, and everything that is in that workplace has to be taken positively because if you are not going to follow what is being set in your workplace, then you will be one of those people who will be a candidate of losing your job because you don't try to mingle with the people you work with. I think it is better to blend in with them and follow what they imply or what they impose rather than going against it." (R3)
"You will be with them every day, you will see how they interact with each other. You will see later on what you should and should not do according to their culture until you can also adapt their delicacies and their clothing. " (R7)

"When it comes to clothing, well I'm not the type who wears spaghetti straps and shorts, I just wear those things at home but not outside. I was shocked, not totally shocked, when I saw people wearing abayas and hijabs because I'm not used to it. When I arrived here, I wore one, but I didn't know that it was okay not to, so when I found out, I wore whatever I wanted compared to other nations. " (R3)

"Clothes and religion are not a problem because I was able to work with Muslims back home, I didn't find any difficulty working with them because they don't even interfere with what Christians believe. I think those are the challenges that I face working with them, but other than that, there's nothing more." (R3)

Some of the respondents on the other hand have already experienced working abroad. This previous experience made it easier for them to adjust to the different culture in Qatar. Also, they have expressed ease in adjusting to the Islamic and Middle Eastern background of the setting. They described it in these responses:

"Since I have prior experience abroad, I've been to Africa so I'm quite adapted to situations like this, and coming here to Qatar there are similarities particularly on the religious aspect which I follow. " (RI)

"I didn't have much of a struggle since Qatar's culture is based on Islamic culture so I didn't have much of a hard time to adapt to their culture." (R5)

\section{Livelihood}

The needs of an overseas Filipino worker also cannot be ignored. The money that they earn from their jobs is used to sustain their needs as well as their families. Expectations may sometimes not be reached because it depends on the job that the worker will land on. The reason why Filipinos often go to another country is to get a better offer for their work and efforts. That is why they choose to embrace these problems that they encounter because they really need the job. Here are some of the experiences of the Filipino Educators that chose to work overseas:

"I expected to encounter multiple challenges, for example, language barrier between me and my students, working with teachers of different backgrounds, being alone, andchallenges not only in school but also at home or in other places." (R4)

"Challenging because we are in a setup where we don't hold specific groups of kids, we don't only teach Qataris but we have a lot. It is a really big challenge because we don't only deal with the kids and their learning abilities but we always deal with their parents and it's totally hard." (R1) 
As with getting accustomed and establishing oneself to a new work environment, there will always be struggles and challenges. One challenge Filipino educators face is discrimination when in regards to work benefits and salary. Because employers have a low opinion on Filipinos, they are given fewer privileges and benefits. Other nationalities have better work benefits compared to Filipinos. Respondents have stated:

"I expected a higher wage or salary however it didn't work that way. I expected to have what other foreign nationalities are experiencing like having a higher pay, accommodation, and a new car but I didn't have the chance to have one." (R3)

"One thing is about the salary. When it comes to not only the Filipino, but the Asian staff, the salary offer is different compared to the Western staff although the duties are the same. We're discriminated against not because of nationality, it's on the income offer to a particular staff. They are, however, treating every staff fairly and normally." (R6)

"That's really the sad part of being an educator here, because we have less privileges. Compared to other nationalities, they get more benefits, but us Filipinos, we just tend to accept whatever is given because that is what we agreed upon. Filipinos are okay with it rather than having nothing. " (R1)

\section{"Difference in salary tickets." (R2)}

"Salary is the first thing, because they earn way too much than we do. The salary and wages are actually the reasons why we come here and work abroad. They're payed more than us, they have their accommodation, a fancy and fully furnished one compared to us, that we had to rent a small place or live in someone you don't even know or someone you just met, and you have to share a room. They got a chance to have their own cars and travel and enjoy dining in restaurants but at least one good thing is when you got the chance to feel like you are one of them, when you work with them and when you seat with them in one conference table, when you're the only Filipino there, it'll feel like best day of your life. Other than that, enjoying becoming a professional development with them but the salary, wages, accommodations, and transportations is totally a different story." (R3)

"Our salary is different from those teachers who are from UK or South Africa because they say we are just Filipino and I think they also base it on the cost of living in a certain country that is why we are given different benefits. Actually, we have the same job. I work even harder than them because once they have a certain problem, they address it to Filipino teacher." (R5)

"I don't see anything. Most of us or a lot of us in our company or school, know the level of our benefits. We know how little we receive compared to the others. That doesn't stop us from performing the best that we can because we don't look at the others, we were properly trained and we were trained to give our best no matter what. That's the good thing about Filipinos because no matter how little you get in the company; your performance does not change." (RI)

"In our system, if you are an English teacher, that is the only field you will be teaching. Although, the benefits are the same with colleagues teaching different subjects. " (R7)

Another challenge that the Filipino educators struggle with is discrimination occurring in their workplace. It is a big struggle for the teachers to work with different nationalities with different cultures and traditions most especially when they are faced with unfair treatment by their colleagues. Naturally, they feel the distance and borders between them and their co-workers since discrimination itself mainly covers the grounds of race and the difference in terms of culture. The respondents have said:

"Yes, because I started as an English as a second language teacher it felt like I was given more work than the other teachers however as time passed I realized that this was my job and so I needed to do this." (R5)

"Before I transferred to a government school, I worked in a British school as a grade one teacher. There's a big difference. The discrimination was evident. The students were in groups: Asian with Asians, white with the whites. Even our salaries were based on our passports. But in the government school, our salaries and responsibilities are equal and balanced, even though we don't reside here." (R7)

As educators, they also have to instill discipline into their students. However, due to a difference in culture and customs, it may be difficult to communicate and properly deal with the negative attitude and behavior of students. The educators must find ways to overcome these challenges and act accordingly. The respondents have said that:

"The most challenging part was the behavior of the students who come from different cultures for example Qatari people. Their behavior is the total opposite of the Filipino students." (R5)

"Usually we escalate it to administration. We don't deal with those kinds of things. That's the good thing about it, because in the school that we are in, we deal with everything and we escalate them to our administrations." (R1)

Educators do not only focus on the growth of their students but they must also keep in contact with the students' parents. Communication with parents can be done through phone calls, e-mails, or a conference between parents and teachers. However, because Filipinos are being looked down upon by parents of different nationalities, especially in a foreign setting, the educators feel that it is better to just go along with the parents. Several factors such as language barriers and miscommunication may also worsen the situation. The respondents said:

"Sometimes even if you explain to them, they don't understand the situation and all they want is for you to 
understand them and they think that they are always right." (R2)

"The good thing about it is we come to an agreement where we usually give in to the parents but the sad thing about it is, we just give our responsibility to the parents without looking at ourselves. We usually have the parent's consent in dealing with everything like complaints. It's sad that we just have to say "yes" to all the things that they are saying. " (Rl)

"The parents and the kids are the same. Some parents feel more powerful since they have this house helper who is Filipino sometimes, they look down on us unless we prove ourselves." (R5)

"Fortunately, I'm able to work in a school where most of the parents are educated so they are not the type who shouts at teachers unless they are new to the school. Actually, it happened 2 years ago, when a parent just barged into the class, not my class, I was there to support my student and then I was about to take the child out of the class, but the mom just barged in and asked "Where is my child? Where is he?" Her child was outside in the football field with a different class because he was misbehaving. Her child got a black card so she has to be called in the school and explain to her what happened to her child and how the child behaved. That child came from an Arabic school and then transferred to an English school so he has language, leaning, and behavior problems and the teacher had to deal with that. That teacher mastered in special education but she was not able to tame the child. Only at the end." (R3)

\section{DISCUSSION}

\section{A. Sociability}

According to Aristotle, a Greek philosopher. Humans are social beings; therefore, we seek for companionship. Today, humans are socializing to have a sense of happiness and completion in their life. People are always seeking joy and feeling of fun at work for a greater engagement at work [17].

As a migrant, it is normal to feel like you are out of place and where is the best place to be able to communicate with people rather than work. Being able to communicate in their workplace greatly affects the employee service innovative behavior that enhances their work attitude [18].

Being able to communicate with people you see every day is not only a way to feel a sense of completion but people usually communicate to recharge and relax, thus, inspiring them to continue with their work. Being Able to communicate in the workplace has a benefit to their output [19] and can also be a channel of information flows between co-workers [19].

Today, leaders are expected to start a conversation between their members, but this should not be the case. A simple communication between workers allows them to feel a sense of belongingness in their workplace. Great work environment does not always depend on its leaders, a mere positive and significant influence on work engagement such as socializing allows employees to create a positive workplace behavior [20].

Living far away from your family and friends tend to lead expatriates to a feeling of emptiness in situation, to cope up, they go out after work hours with friends either from work or from social circles that allows them to refresh their mind. Socialization in a particular form engages a positive impact in the employees' work moral [21].

Working with people of varied cultural backgrounds is intimidating. Socialization boosts confidence at work as an individual with differences which allows workers to equate success and failures with their co-workers [22]. Socializing is a way for people to understand each other and meet the needs of diverse learners [23]. Socializing will also allow them to realize that their perspectives or methods of teachings should be based as to what their learners are comfortable with [23].

Restricting workers to communicate during office hours may lead to misunderstanding between them. Not being able to communicate in their workplace is a challenge for them to understand the norms and practices of their workplace [24]. Yet, a little recognition goes a long way. Being able to communicate with others allows them to be recognized in their workplace where their capabilities are valued [24]. Being able to communicate usually leads to actions that are impersonal or leads to the inability to meet the individual's needs [25].

\section{Language}

Communication is a significant adaptive strategy for migrants to adapt into their new environment. Several Authors have highlighted in their studies how communication between non-native speakers and native speakers is a significant and an effective way to cope with language barrier [26].

When Migrants travel and work abroad it is inevitable to face struggles and challenges along the way. One of these challenges is Language Barrier. It is normal for migrants to tend to their adjustment problems by inventing creative pragmatic solutions in their predicaments [27].

One of the ways migrants cope with language barriers is through interactive conversation. By doing playful exchange of ideas, storytelling and hand movements as a way to send a message across [28].

As a teacher abroad where the majority of your students speak their native language it is indeed hard to cope up and interact with them yet despite this. Communicative skills can be seen to develop in classrooms overtime. Communicative skills that can increase their interactivity outside the classroom and to cope with language barrier [26].

Another way that migrants cope with language barriers is through the use of communicative technology to increase the interaction in their classrooms. Throughout the years 
technology has been a highlight tool to help increase the interaction and blur-socio differences [26].

Nonverbal Communication is another way used by foreigners to cope with language barriers. Simply sharing of information through non-spoken symbols or non-voiced communication are some of those [26]. Such as the use of objects to show what they feel or a way to dialogue with each other so that they could identify a common ground [28].

However, what happens when you are communicating with a person who does not know enough in their own language and at the same time you are communicating with them in a totally new language. Enters phonics instructing, migrant teachers make use of phonic teaching to teach their students basic English words, objects, phrases and such [29]. Despite phonic teaching, teachers still observe that their students do not pay attention to what they teach and in return they do not learn basic components of reading [29].

In the long-term teachers have then noticed that even if their students were struggling. They still try to reach out intentionally to seek information through the use of gesture [28]. Their students are then inventing imaginary words or words that are close to what they mean to fill the gap of their sentences [28].

Lastly, to allow their students to understand that their teachers are trying to send a message across. They make use of activities including sharing of ideas and experiences including student's participation so that students will be able to seek and receive information [28].

\section{Approach}

Teachers who have traveled and worked abroad can help them become qualified teachers. Working abroad gives teachers the edge to be flexible because of the varied cultural background of their students. They pay attention to pedagogical issues that are accepted by their students [30].

It allows teachers to observe and learn how teachers in other countries teach. They learn different classroom management, develop flexible lesson materials, useful ways to motivate students of different cultures and personalities and create a classroom where students and teachers can easily communicate with each other [30].

However, one of the struggles that teachers face while working abroad is the difference of culture. A difference in culture that creates hurdles in norms, ethics, and values in the working environment [31]. They experience a huge cultural difference between their home country and host countries, which requires adjustment to the host country [32].

They are usually in doubt of their actions so as to not offend others. This is why it is very crucial for them to know the values and beliefs of different cultures [2].

For passionate teachers it holds an important place in their heart to learn about the language and culture of their students to promote attitudes that encourage their students to learn [2].

The greatest advantage of an international experience is knowing different cultures and learning about the life of the people from different nations. Which allows them to be aware of the needs of their students to provide effective education [2]. Yet despite the advantage many things are still prohibited from what they are used to, which is why they must respect the local culture of the host country [31].

And conflicting with co-workers was stressful for expatriates. To prevent such stress, they are immersed in training that allows them to understand the values of their host country [32].

Training that focuses on how expats could adjust to their new environment are provided for them [34]. Training such as cross-cultural training that intends to make expatriates feel confident in foreign assignments. Training that improves their adjustment and increases their knowledge and appreciation in different points of view [31].

Lastly, working abroad allows them to obtain new skills or improve existing skills they have, it stimulates them to think and work in different mindsets. And this experience will lead them to international work opportunities [34].

\section{B. Personality}

Work plays a fundamental role in adulthood which sustains an individual financially. Along with the work environment and experiences comes the development of one's values, social roles, and activities on a daily basis [35]. These work experiences will shape how an individual thinks, feels and behaves that gradually become enduring attributes of one's personality [35]. Consequently, this can significantly modify one's personality to fit and adapt to their work environment.

The term 'workplace learning' has gained many definitions over time. It is generally depicted as a link between work and learning in human development [36]. This correlation may refer to the interaction between the individual and the social environment that stimulates the development of competencies and leads to a behavioral change [37]. These personal developments and changes inevitably influence one's personality especially when faced on a daily basis.

Resettling to a foreign setting is contended with the fear of unknown anxiety on those being left behind and a sense of imminent loss [38]. Personal characteristics and situational context are relative determinants to an individual's coping response in an unfamiliar environment [38]. The immigrant employees' losses in social connections prove to be a cause of identity struggle, wherein it is accompanied by a drop in status recognition and respect from others [39].

The Middle East is fairly a popular destination for Overseas Filipino Workers (OFWs). These millions of Filipino workers in the Middle East make and contribute billions to the Philippines and have become one of the 
country's largest sources of foreign exchange income [40]. Qatar, having the highest proportion of migrants to citizens in the world, is greatly dependent on foreign labor [41]. This opens plenty of job opportunities for Filipinos, which results in the increasing number of Filipinos being deployed and working in Qatar [42]. One of these job opportunities includes foreign educators in international schools. In improving the educational quality of schools, the professionalism of educators plays a significant role [43]. This makes Filipinos, who are known to be determined, hardworking, and resilient, ideal for these job positions [44].

Due to the ongoing internationalization, Qatar is hiring foreign educators and leaders to exchange expertise and experience in their country [45]. The educators have to comply with the certain guidelines and policies of the international schools in Qatar. Correspondingly, the Filipino educators have to adjust their accustomed behaviors in their former country to the behaviors that obeys these regulations [45].

Adjusting to all these circumstances and restrictions in an unaccustomed environment abroad can be mentally damaging [46]. This leads Filipino educators to develop personalities that help them cope and fit to the educational and living setting in Qatar. Our study classifies these personalities into either Interpersonal or Intrapersonal personalities.

\section{Interpersonal}

Acculturation changes a person's psychological and behavioral repertoire. It is a process by which individuals change, both by the influence of another culture through direct liaison and by participating in general acculturative changes ongoing in their own culture [47]. Adapting to the new work setting, employees had to consider the disparities between the current country's customs and the previous. This indicates that understanding the local culture and feeling psychologically comfortable in it might be necessary for expatriates to pursue their professional cause effectively [48].

Filipino workers are most associated with the traits and cultural values of flexibility and easily getting along with others [49]. Thus, Filipino educators deemed it easier to acclimate by means of working with their associates. Social support can be related to aspects on a personal level provided with certain circumstances [50]. Trust in others and social participation are parts of social capital integrated with good mental health. Furthermore, trust in others and a sense of belonging moderate the relationship between perceived discrimination and mental health. Building trust increases the interest and responsibility among educators, which creates dedication and commitment in the workplace [51].

Expatriates will encounter receptivity and conformity pressure in the workplace in the same manner as in their general setting [52]. The receptivity of local employees and their identification of expatriates whether they are considered part of the group or not will affect work adjustment [52]. As observed in our findings, instructions and evaluations received from colleagues with varied cultural backgrounds impels Filipino employees to progress in their expertise as well as their personal facets. Moreover, when immigrants feel socially integrated with the workplace, it indicates that colleagues and supervisors accept and interact with them [53].

The need for an accommodating ambiance for educators with varied cultural backgrounds guarantees them to develop cultural awareness, promote acceptance, and take social initiatives [54]. Educators need to engage and cooperate with one another in a coordinated workplace in order to create a balanced and harmonic environment wherein language learners and native English speakers can progress academically [55].

Our study has shown that overseas Filipino workers were able to grasp customs and values from their foreign colleagues, conversely, colleagues learn from them, creating an engaging and inclusive work environment. Socialisation and association of accompanied expatriates with host country nationals lessen the symptoms of homesickness as they find significance of their new reality [56]. The knowledge and skills acquired by being in contact with their host culture and home culture complements the individual's career advancement and benefits organization development in the workplace [57].

Multicultural education is to be promoted to ensure a world which is truly global where people of different races, nationalities and ethnicities live in peace and harmony with equality and equity, especially in the present global context where insularity is apparent [58]. Moreover, diversity enhances communication, increases understanding of various cultures and environments, reduces discrimination and ensures fairness and equity in an organization [59].

\section{Intrapersonal}

Skills of self-management [60], self-awareness, regarding one's own strengths and weaknesses, and one's openness to change are forms of intrapersonal competence [61]. The educators should have the willingness to learn and continuously improve themselves, capability of ethically assessing themselves and their colleagues, tolerance for other people's opinions, and self-confidence to enable essential change for the team [61]. The application of these intrapersonal skills to the workplace can also likely ensue to better interpersonal interactions [60], which is reflected in our findings. Developments were brought on by intrapersonal reflections stemming from training, which inflicted changes in perceptions of and interactions with others [62].

Motivation stimulates direction, intensity, and persistence of action, and the channeling of an individual's psychological resources towards accomplishing particular goals [48]. Having control of their mental state and capability to maneuver their tasks "through the mental exercise of selfreflection" [63] as they adapt to the foreign workplace allowed the Filipino expatriates to have a sense of fulfillment. 
Individuals with high degrees of autonomy, competence, and relatedness viewed the challenges presented in the period of adapting as the opportunity to elevate their conscious awareness and set a personal goal to resolve the conflict [64]. Participants evinced that they managed to surpass obstacles by focusing on setting goals, accomplishing their duties and viewing them as drives for personal development. This implies that it is increasingly vital for expatriates to continuously look at ways they can improve their existing skills or gain new expertise while they are taking international assignments [57].

Appraising employees' performance is agreed to be beneficial to organizations and simultaneously creates motivation for the employees [65]. Human nature's desire to be recognized and appreciated for their work performance compels them to initiate action to new challenges and to be innovative substantially [66]. This perception encourages Filipino educators to identify themselves positively and effectively increases their enthusiasm to do more. Moreover, respect gained from host culture individuals inspires, motivates and makes them feel proud about their profession [67].

The evident dissimilarity in the workers' salary between their previous workplace and their current depending on the employee's demographic support them to grant the needs of their family to live a happy life to a greater degree. Educators consider the financial and fringe benefits as the dominant key constituents of motivation which minimizes and converts the issues and problems into better work practices [67].

Workers spend a significant proportion of their lives at work, feelings and satisfaction about their workplaces have a substantial impact on work productivity and psychological well-being [68]. Working currently in international schools, Filipino employees accounted for the reduced stress and pressure in contrast to their previous workplace. Additionally, well-being at work is best achieved when employees feel a two-dimensional sense of meaning and purpose along with a sense of contentment toward their profession [69].

\section{Adaptability}

The formal exportation of laborers in the Philippines first started in 1973, when former President Ferdinand Marcos approved of the export-oriented policy due to the rising contractual labor opportunities present in the Middle East [70]. However, settling in another country provides Overseas Filipino Workers (OFWs) a need for many adjustments. Expatriate workers experience huge differences between their life in their home country and their host countries. They have to change their lifestyles and ultimately get stressed with that need [32]. Difficulties such as emotional stress, challenges, as well as strategic coping mechanisms and resources were faced as they tackled adapting to a different country. Some external challenges that were regularly faced even include diet differences, living habits, and weather [71]. In relation, expatriate Filipino teachers, in particular, can face challenges like simultaneous student requests, lack of time and resources, inadequate professional support, varied student behaviors, and the lack of constant change which may differ from what they got used to in their previous environment [103].

Globalization also makes way for the movement of teachers internationally and provides teachers a way of traveling abroad. It becomes a way for highly-trained professionals like them to leave their home country and earn more [73]. Qatar is an example of a main destination for Filipinos who look for overseas work opportunities. In the Philippine Overseas Employment Administration (POEA) report from 2009, a total of 669,042 Filipinos who work in the Middle East, with $13 \%$ being employed in Qatar [45]. It makes it one of the countries that have a high percentage of Filipino expatriates employed in different companies that are based there. This gives an advantage to Filipino teachers who seek out employment. Filipino teachers are often sought as capable employees as they are good with the English language, hardworking and diligent workers, and supportive in terms of working environment relationships [74]. Despite the advantages, disadvantages can also rise. Possible miscommunication in understanding the locals and their practices there could lead to conflicts [75]. This makes cooperation with other people and adjustment very important in living in a different environment in another country such as Qatar.

Teachers are also tested in terms of proving one's sense of flexibility in making positive changes. This is present not only in the classroom but also among fellow teaching staff and the school where they work. This is significant as it demands the accomplishment of their work as they adjust to the roles and social situations given, especially in international schools [76]. The challenge becomes more difficult as they embark on these in a foreign setting. Their teaching styles may also be in advantage or disadvantage, depending on their individuality as these depend on factors such as the learning process, learning nature of the learner, and learning situation [77]. In addition, transfers to another school can also be very taxing at an intellectual, social, and emotional level for teachers. However, it can also be rewarding as an opportunity to grow and develop as an individual [11]. The growth and development could then easily manifest part of their identities to construct a role that engages them to interact with other cultures and identities as they experience these in an overseas environment [79].

\section{Culture}

Adaptation is also a social and cultural exchange. It depends on the individual's own volition whether he or she will settle with the possibilities of a new socio-cultural environment, or if the idea of having new connections and relationships are denied and rejected [80]. An individual's ability to adapt to foreign culture depends on the difference between the individual's own culture [81]. As stated by [81], "a large difference between the country of origin and the destination requires more transitions, which results in more adjustment difficulties than in a country with a similar culture." In other words, adapting is more difficult when the host country is more culturally distant [82]. Individuals may also have been subject to similar cultures making it easier to adapt to their current environment. Adaptation process begins 
with culture shock and involves continuous and active engagement and communication within the culture. This also applies in foreign work environments.

Working in a foreign setting is a new experience. Adjusting to their environment requires them to adapt to foreign religion and beliefs [84]. Achieving intercultural communication with students and colleagues requires patience, tolerance, and consideration for cultural differences [85] because language and culture are closely related [86]. Otherwise, cross-cultural issues may arise such as language barriers and teaching impediments [102]. These issues affect the educators' performance within the workplace [88]. Discrimination and isolation are also present in the workplace against Filipino educators similar to those in previous studies [33]. Findings show that other nationalities offered more benefits than the Filipino educators. The educators cope with these by bearing with it or adapting.

\section{Livelihood}

Many of Qatar's guest staff, from high-wage expatriates to low-income migrant workers with low wages are regulated by a scheme of sponsorship known as kafala. The control of foreigners is delegated to the citizenry under the scheme, whereby the visa and residency permits of the worker are attached to his/her kafeel, or sponsor [90]. The choice of a migrant to migrate is affected both by supply and demand considerations. The supply side of foreign migration is influenced by economic and non-economic benefits, motivating individuals to join in cross-border movements. Conversely, the demand side is reflected by the need for immigrants in the destination market as well as the immigration policies in effect. If the perceived utility of living abroad is greater than the payoff of remaining in the home economy (net of migration costs), a person will then prefer to migrate [91]. As the Filipino migrants continue to rise, they are being known as renowned migrants to different parts of the world and are globally recognized with their professional workforce [92]. Filipinos are known to work outside of their home country not only to receive higher amounts of salary but also to help provide for their families. Filipino teachers in particular mentioned that professional development, better standards of living, family migration, and salary difference are some of the reasons why they work overseas [93]. When it comes to financial inclusion, religion helps to overcome the asymmetry of financial data and render the usable financial and non-financial services available to the otherwise financially excluded members of the Philippines [94]. It is also proven that Filipino educators can sustain their families financially in research conducted before. Filipino parents and educators can support the academic success of their children [95]. In reality, Filipino workers are also facing different challenges aside from leaving their families in the Philippines to have a better future. Communication, finances, life and work environment are some of the challenges they encounter in their everyday lives [96]. However, moving to another country can be difficult as the results of going abroad can be uncertain. One must risk the possible challenges that might be faced in the foreign region, and learn how to take every given opportunity until he or she finds a better job [97].
Filipino teachers are said to be in demand due to their abilities to adapt to any work environment however, the Filipino teachers are pressured in terms of improving their teaching methods as well as seeking a route to improve their professions to ensure that their employers will renew their contracts yearly [70]. Despite the difficulties that the Filipino teachers face, they chose to retain their innate happiness and to not regret the path they have chosen for themselves. Education system decision-makers could implement measures to help with the transition of expatriate teachers so the teachers may continue to serve as part of the solution to their shortages [73].

For most of the migrant workers, labor migration is not just a one-time, temporary means of livelihood, it has become their way of life.A part of living abroad requires constant alertness and informed decision making with regard to designing policies and programs that look after the welfare of migrant workers [98]. Internationalism and dominant nationalisms call upon good Filipinos to serve the country and the world through their migration away from their hometown and the returns on their labor and migration which does not only benefit them but a lot more people [99]. Despite the challenges that they are facing, as Filipinos, there are times that they have proved to beat those challenges. Teachers face a number of tensions that describe their lived experience in making sense and operationalizing curriculum policies in their classroom which includes being confused yet appreciative, being frustrated yet flexible, and being powerless yet vital [100]. With the saying "adaptation and survival entail goals and a set of positive attitudes," the Filipino educators undertake the challenge of working abroad in order to accomplish professional development and their growth as a person [101].

\section{CONCLUSION}

Filipino educators are constantly facing opportunities overseas that are paired with difficulties they need to overcome. Adjustment to a new environment does not often come easy, often becoming challenges for these educators' personal and professional lives. Difficulty in communication in another country due to language barriers can occur, especially among peers and students alike [4].

Adaptation of Filipino educators was needed to ensure their survival in the difference and stress of adjusting to their new lifestyle in their host countries [71], especially in the extreme temperatures of an expatriate hub country like Qatar [45]. Adaptation in a foreign work environment is successful when the Filipino educator has a similar culture to their current environment after they surpass the culture shock, and continuously involve themselves in their host country's culture [35]. As stated by Watanabe [84], adjustment to the new experience requires their ability to adapt to the foreign religion and beliefs, as well as cultural tolerance and consideration for both the student and the educator [85]

However, issues such as discrimination and isolation can be present [33], and can affect the performance of the 
Filipino educators. This is usually seen when nationalities are offered more benefits than the Filipino educators, despite having the same position. The respondents experienced situations where there is a difference in salary wages as well as behavior between them and other nationalities. In relation, Filipino teachers particularly prefer the overseas setting due to the professional development, better standards of living, family migration, and salary difference that are more favorable [93]. The Filipino educators face a number of tensions that can make them feel conflicted feelings at times [100]. Despite that, they still undertake the challenge of adapting and taking the challenge of working abroad in order to accomplish professional development and their growth as a person [101].

A Filipino educator's personality can also be molded by work experiences to easily fit into their work environment. [36] states that workplace learning is correlated with human development. This type of development can greatly influence the Filipino educator's personality, more if identity struggle and recognition and respect from others are failed to be achieved [39]. As they are overseas, the educators are required to comply with the policies present in Qatar's international schools. They also had to align their behaviors in order to successfully follow these regulations [45]. These can mentally deter them [46], and lead to changes and development of personalities that aid them cope in the setting in Qatar.

Different work settings also give way to the opportunity of understanding the local culture of the host country [48]. The respondents have described that they were able to learn to live with the customs and values of their foreign colleagues and learn from each other's own customs, creating a sense of harmony between both sides. Socializing and associating with host country nationals can create a sense of belongingness and lessen homesickness in expatriates [56]. The diversity of the setting of multicultural education and in relation work environments also increases the chances of deeper understanding of varied cultures, and promotes equality [59]. It convinces the Filipino educators to willingly improve themselves, as well as be more tolerant to the other factors that surround them [61]. Despite the salary gap between their previous and current workplaces, their priority remains to be able to financially support their families, and often take salary into consideration when it comes to self-motivation of professional improvement [67]. It is also noted that the difference in environmental stress is evident for the Filipino educators. This comes at ease, however, when employees are able to find purpose and meaning of contentment in their profession [69].

Socialization is very important for humans but as migrants, it can be difficult to communicate with the people in their new working environment. Workplace communication can increase a worker's overall performance [20]. As it is common for expatriates to feel homesick, socializing with new friends can positively impact their work morale [21]. Socializing with people in the workplace can also help the educators to understand and adapt to the workplace norms and traditions [24] as well as to the learners
[23]. However, due to being in a foreign country, there is risk of encountering language barriers. Several authors say that constant communication through different means can be used to cope with language barriers [29.]

There are a lot of ways to help the Filipino educators in order for them to effectively communicate with their colleagues or students. For passionate teachers, learning about the language and culture of their students is an important place in their hearts to foster behaviors that inspire their students to learn [2]. They are provided with training that focuses on how expats should adapt to their new world [34]. Training that helps to make expatriates more secure in international assignments, such as cross-cultural training. Training that improves their adaptation and increases their understanding and appreciation from various points of view [31]. Lastly, working abroad allows them to obtain new skills or improve existing skills they have, it stimulates them to think and work in different mindsets. And this experience will lead them to international work opportunities [34].

The results of this study provided insight to the different experiences of Filipino educators working in foreign environments. The study explored the behaviors and reactions of the educators. These experiences, gathered through structured interviews, can give awareness to other educators looking to work abroad as well as assist other researchers pursuing similar courses of studies. The coping mechanisms developed by the respondents can serve as references for individuals who find themselves in a similar situation.

This paper has limitations as any other study. First, the study is centered on the lived experiences of Filipino expatriates teaching in an international setting located in Doha, Qatar. Other countries wherein Filipino expatriates who teach in foreign systems have not been included in this study. Second, researchers are not able to further gather and instigate a wider range of responses due to the small sample size. Moreover, the researchers noticed that the respondents tend to wander off during the interviews which gave irrelevant responses to the study being conducted. Future studies are recommended to have a larger sample size for supplementary responses. It is also suggested for future researchers to conduct interviews with more specific questions relating to the lived experiences of expatriates in a foreign setting and to examine influences of the foreign environment to other outcomes, for example, educators' job satisfaction or future intentions.

\section{REFERENCES}

[1]. Ragma, F., \& Molina, J. F. (2018). Angst Of Warriors: The Fears Of Overseas Filipino Workers (Ofws). Retrieved From DOI: 10.13140/RG.2.2.24373.17126

[2]. Serin, H. (2017). The effects of teaching abroad on personal and professional development. International Journal of Social Sciences \& Educational Studies, 4(1), 110-114. doi: http://dx.doi.org.eres.qnl.qa/10.23918/ijsses.v4i1p110 
[3]. Livholts, M., \& Bryant, L. (2017). Social Work In A Glocalised World. Oxfordshire, England: Taylor \& Francis.

[4]. Ulla, M. B. (2018, November 18). English Language Teaching in Thailand: Filipino Teachers' Experiences and Perspectives. Retrieved November 22, 2020, from http://www.iier.org.au/iier28/ulla2.pdf

[5]. Añar, L. E., Petersen, R. J., \&Villanca, A. A. (2016). The Learning Experiences of Filipino Pre-Service Teachers In The Science, Technology, Engineering And Mathematics (STEM) Program Of A Thai Elementary School.

[6]. K. Barad, "Diffracting Diffraction: Cutting TogetherApart," Parallax, vol. 20, no. 3, pp. 168-187, Jul. 2014, doi: 10.1080/13534645.2014.927623.

[7]. Goren, H., \& Yemini, M. (2015). Global Citizenship Education In Context: Teacher Perceptions At An International School And A Local Israeli School. Compare: A Journal of Comparative And International Education, 46(5), 832-853. Doi:10.1080/03057925.2015.1111752

[8]. Cruz, K. V., Cruz III, R., \& Yap, J. M. (2018). Challenges Of International Librarians: Knowledge Sharing From Filipino Librarians Working Across Asia.

[9]. Johnson, R. (2018). LIVED EXPERIENCE OF MIGRANT FILIPINO REGISTERED NURSES IN NONPROFIT HOSPITALS IN CALIFORNIA.

[10]. Carpio, G. J., De Torres, A. L., Samiran, R., Villera, K., \&Manguerra-Mahusay, S. (2018). Work and Travel Experiences Of Filipino Tourism Students In Selected Universities. Retrieved fromdoi: http://Dx.Doi.Org/10.15206/Ajpor.2018.5.2.143

[11]. Paik, S. J., Choe, S. M., \&Witenstein, M. A. (2016). Filipinos In The U.S.: Historical, Social, And Educational Experiences. Social And Education History, 5(2), 134. Doi:10.17583/Hse.2016.2062

[12]. Mohajan, H. K. (2018). Qualitative Research Methodology In Social Sciences And Related Subjects. Journal Of Economic Development, Environment And People, 7(1), 23. Doi:10.26458/Jedep.V7i1.571

[13]. Cresswel\& Plano Clark, 2011, as cited in Palinkas et al., 2016

[14]. Vallesteros, F. A., Recato, A. J., Ucang, J. P., Canaria, R. R., \& Mariano, A. G. (2020). Taking Stand Behind the Bars Of Lies: The Toxicity Of Cyberbullies Among Students. Doi:10044112020894

[15]. Curtis Newbold, 2018

[16]. Vallesteros, F. D. J. A., Demonguitan, J. C., Fernandez, K. D. M., Magdael, R. R. G., Dolojan, J. D., Magadia, C. M. C., ...

[17]. S. Xu, Y.-C. Wang, E. Ma, and R. Wang, "Hotel employees' fun climate at work: Effects on workfamily conflict and employee deep acting through a collectivistic perspective," International Journal of Hospitality Management, vol. 91, p. 102666, Oct. 2020, doi: 10.1016/j.ijhm.2020.102666.

[18]. Al-Hawari, M., Bani-Melhem, S., \&Shamsudin, F. (2019). Determinants Of Frontline Employee Service Innovative Behavior: The Moderating Role Of Co-
Worker Socializing And Service Climate. Doi: 10.1108/MRR-07-2018-0266

[19]. Park, S. (2019). Socializing at Work: Evidence from a Field Experiment with Manufacturing Workers." American Economic Journal: Applied Economics, 11 (3): 424-55. Doi: 10.1257/app.20160650

[20]. Al- Hakim, M. L., \&Soetjipto, B. (2020). The Effects of Leader-Member Exchange and Fun at Work on Work Engagement and Deviant Workplace Behavior in Indonesian Telecommunication Company. Doi: 10.18502/kss.v4i6.6603

[21]. Cekaite, A., \&Evaldsson, A. (2020). The Moral of Emotion Work In Adult-Child Interactions. Doi: Https://Doi.Org/10.1515/Text-2020-2082

[22]. Mellor, S. (2019). Confidence at Work and Individualism-Collectivism: An Empirical Demonstration Of The Distinctiveness Of American Union Employees. Doi: https://doi.org/10.1007/s12144-017-9636-2

[23]. Varghese, R. (2020) Teaching without being taught how: social work practice faculty voices, Social Work Education, $\quad 39: 2, \quad 145-159, \quad$ DOI: 10.1080/02615479.2019.1619684

[24]. Rajendran, D., Farquharson, K., \&Hewege, C. (2017). Workplace integration: the lived experiences of highly skilled migrants in Australia. Doi: 10.1108/EDI-112016-0094

[25]. Ramarajan, L., \& Reid, E. (2020). Relational Reconciliation: Socializing Others across Demographic Differences. Doi: https://doi.org/10.5465/amj.2017.0506

[26]. Elega, A. A., \&Özad, B. E. (2017). Technologies and second language: Nigerian students' adaptive strategies to cope with language barrier in northern cyprus. Journal of International Students, 7(3), 486-498. doi: http://dx.doi.org.eres.qnl.qa/10.5281/zenodo.570011

[27]. Yu, K., \&Shandu, B. (2017). Overcoming language barriers: Lessons learnt from migrant children. Perspectives in Education, 35(1), 157-170. doi: http://dx.doi.org.eres.qnl.qa/10.18820/2519593X/pie.v $35 \mathrm{i} 1.12$

[28]. Saneka, N. E., \& de Witt, M. (2019). Barriers and bridges between mother tongue and english as a second language in young children. South African Journal of Childhood Education (SAJCE), 9(1) doi: http://dx.doi.org.eres.qnl.qa/10.4102/sajce.v9i1.516

[29]. Sadeghi, M., \&Izadpanah, S. (2018). Barriers in teaching reading to ELLs and ways of overcoming those obstacles. Journal of Language Teaching and Research, 9(2), 295-301. doi: http://dx.doi.org.eres.qnl.qa/10.17507/jltr.0902.10

[30]. Çelik, B. (2017). The effects of working abroad on the development of teaching skills. International Journal of Social Sciences \& Educational Studies, 4(3), 212215. doi: http://dx.doi.org.eres.qnl.qa/10.23918/ijsses.v4i3p212

[31]. Noman, M., Muhammad, S. S., Talles, V. B., Hwang, J., Muhammad, Y. B., \& Thai Hong, T. K. (2020). Determining the challenges encountered by chinese expatriates in pakistan. Sustainability, 12(4), 1327. doi: http://dx.doi.org.eres.qnl.qa/10.3390/su12041327 
[32]. Doki, S., Sasahara, S., \&Matsuzaki, I. (2018). Stress of working abroad: A systematic review. International Archives of Occupational and Environmental Health, 91(7), 767-784. doi: http://dx.doi.org.eres.qnl.qa/10.1007/s00420-0181333-4

[33]. Balgoa, N. G. (2019). Filipino English Teachers in Japan: "Nonnativeness" and the Teaching and Learning of English. Journal of Language Teaching and Research, 10(2), 256-263.

[34]. Riva, N., \&Lauw, M. N. (2016). Benefits and challenges of going abroad for research or clinical training. Journal of Thrombosis and Haemostasis, 14(9), 1683-1684. doi: http://dx.doi.org.eres.qnl.qa/10.1111/jth.13412

[35]. Wu, C. (2016). Personality change via work: A job demand-control model of Big-five personality changes. Journal of Vocational Behavior, 92, 157. https://search-proquest-

com.eres.qnl.qa/docview/1761128182?accountid=4993 6

[36]. Zhao, Y., \& Ko, J. (2018). Workplace Learning in The Professional Development of Vocational Education Teachers.StudiaPaedagogica, 23(2), 43-58. http://dx.doi.org.eres.qnl.qa/10.5817/SP2018-2-4

[37]. Hannah, D. H., Borges-Andrade, J., \& Simone, K. C. (2017). Learning strategies at work and professional development. Journal of Workplace Learning, 29(6), 490-506. http://dx.doi.org.eres.qnl.qa/10.1108/JWL05-2016-0037

[38]. Bhardwaj, V. K., \& Rani, M. (2017). Personality, coping and well-being in Kashmiri migrants' employees and non-migrants employees: A comparative study. Indian Journal of Positive Psychology, 8(4), 512-518. https://search-proquestcom.eres.qnl.qa/docview/1986584689?accountid=4993 6

[39]. Harrison, D. A., Harrison, T., \& Shaffer, M. A. (2019). Strangers in Strained Lands: Learning From Workplace Experiences of Immigrant Employees. Journal of Management, 45(2), 600-619. http://dx.doi.org.eres.qnl.qa/10.1177/01492063187906 48

[40]. Tarrazona, N. T. (2018). For skilled Filipinos, Middle East remains a career destination. (2018, Oct 17). AlArabiya.Net https://search-proquestcom.eres.qnl.qa/docview/2120844182?accountid=4993 6

[41]. Mirasol, J. D. B. (2017). The Philippines' Labor Migration: OFWs in Qatar and the Kafala System. (C) Foreign Service http://hdl.handle.net/11540/7263

[42]. Aguilar, J. (2016). Filipino population in Qatar increases to 222,712. Gulf Times. http://www.gulftimes.com/story/504692/Filipino-population-in-Qatarincreases-to-222- 712

[43]. Nasser, R. (2017). Qatar's educational reform past and future: challenges in teacher development. Open Review of Educational Research, 4(1)http://dx.doi.org.eres.qnl.qa/10.1080/23265507.20 16.1266693
[44]. Barrera, D. J., Gaga-a, B., \&Pabayos, J. (2016). Negative Life Events and Maladaptive Behaviors Among Filipino Adolescents: an Empirical Test of the General Strain Theory. Asian Journal of Criminology, 11(4), 265-287. http://dx.doi.org.eres.qnl.qa/10.1007/s11417-0169230-9

[45]. Del Rosario, K. A., \& Ancho, I. V. (2020). Unfolding of Filipino School Leadership Experiences in Doha, Qatar. Asian Journal of University Education, 16(1), 97-108. https://search-proquestcom.eres.qnl.qa/docview/2459014717?accountid=4993 6

[46]. Eldosougi, I. (2016). 7 Strategies for Embracing Cultural Immersion. Diversity Abroad.https://www.diversityabroad.com/studyabroad/articles/7-strategies-cultural-immersion

[47]. Pekerti, A. A., Quan, H. V., \& Napier, N. K. (2017). Double edge experiences of expatriate acculturation. Journal of Global Mobility, 5(3), 225-250. http://dx.doi.org.eres.qnl.qa/10.1108/JGM-08-20160037

[48]. Wechtler, H., Koveshnikov, A., \&Dejoux, C. (2017). Career Anchors and Cross-Cultural Adjustment Among Expatriates in a Non-Profit Organization. Management International Review, 57(2), 277-305. http://dx.doi.org.eres.qnl.qa/10.1007/s11575-0160307-6

[49]. Nepomuceno, A. (2017, Mar 01). Filipino caregivers: Service with a heart. Business Mirror https://searchproquest-

com.eres.qnl.qa/docview/1873339323? accountid=4993 6

[50]. Jogunola, O. (2019). Factors Influencing Mental Health of Immigrants - A Literature Review. Turku University Of Applied Sciences.https://www.theseus.fi/bitstream/handle/1002 4/169813/Oluwakemi_Jogunola.pdf?sequence=2\&isAl lowed $=\mathrm{y}$

[51]. Han, J., \& Yin, H. (2016). Teacher motivation: Definition, research development and implications for teachers. Cogent Education, 3(1) http://dx.doi.org.eres.qnl.qa/10.1080/2331186X.2016.1 217819

[52]. Haslberger, A., \&Dickmann, M. (2016). The correspondence model of cross-cultural adjustment: exploring exchange relationships. Journal of Global Mobility, 4(3), 276-299. http://dx.doi.org.eres.qnl.qa/10.1108/JGM-05-20160021

[53]. Malik, A., \&Manroop, L. (2017). Recent immigrant newcomers' socialization in the workplace. Equality, Diversity and Inclusion: An International Journal, 36(5), $382-400$ http://dx.doi.org.eres.qnl.qa/10.1108/EDI-11-20160083

[54]. Enoksen, E. (2016). Perceived discrimination against immigrants in the workplace. Equality, Diversity and Inclusion: An International Journal, 35(2), 66-80. http://dx.doi.org.eres.qnl.qa/10.1108/EDI-07-20150058 
[55]. Curiale, J. M. (2019). Shared Viewpoints of ENL Teachers about the Challenges They Face: A $Q$ methodological Study (Order No. 22587686). Available from ProQuest Dissertations \& Theses Global. (2301477270). Doi: https://search-proquestcom.eres.qnl.qa/docview/2301477270?accountid=4993 6

[56]. Hack-Polay, D. (2020). Global South expatriates, homesickness and adjustment approaches. Public Health Reviews, 41, 1-20 http://dx.doi.org.eres.qnl.qa/10.1186/s40985-02000122-9

[57]. Yu, X. (2016). From East to West: A Phenomenological Study of Mainland Chinese Expatriates' International Adjustment Experiences in the U.S. Workplace. University of Minnesota Digital Conservancy.https://conservancy.umn.edu/bitstream/ha ndle/11299/180214/Yu_umn_0130E_16921.pdf?seque nce $=1 \&$ isAllowed $=\mathrm{y}$

[58]. Mohan, B., \& Nair, L. R. (2018). Story Tellingan Effective Pedagogy for Multicultural Education. SCMS Journal of Indian Management, 15(3), 81-90. https://search-proquest-com.eres.qnl.qa/scholarlyjournals/story-tellingan-effective-pedagogymulticultural/docview/2231860121/se2? accountid $=49936$

[59]. Alozie, O. E. (2020). Diversity V Multiculturalism Advantages and Disadvantages Of Workplace Diversity. International Journal of Scientific and Research Publications, 10(01) (ISSN: 2250-3153) http://dx.doi.org/10.29322/IJSRP.10.01.2020.p9720

[60]. Ratten, V., \& Hodge, J. (2016). So much theory, so little practice: a literature review of workplace improvisation training. Industrial and Commercial Training, 48(3), 149-155. http://dx.doi.org.eres.qnl.qa/10.1108/ICT-08-20150053

[61]. Schreier, C., Udomkit, N., \& Capone, R. (2019). A Study on Competencies for Managing Workforce Diversity: Evidences from Multi-National Enterprises in Switzerland. ABAC Journal, 39(3), 1-16. https://search-proquest-

com.eres.qnl.qa/docview/2384070758?accountid=4993 6

[62]. Womack, V. Y., Wood, C. V., House, S. C., Quinn, S. C., Thomas, S. B., McGee, R., \&Byars-Winston, A. (2020). Culturally aware mentorship: Lasting impacts of a novel intervention on academic administrators and faculty.PLoS One, 15(8) http://dx.doi.org.eres.qnl.qa/10.1371/journal.pone.0236 983

[63]. White, B. J. (2017). A Leadership and Professional Development Teaching and Learning Model for Undergraduate Management Programs. Journal of Higher Education Theory and Practice, 17(4), 57-74. https://search-proquest-

com.eres.qnl.qa/docview/1949474439?accountid=4993 6

[64]. Nelson, D. D. (2016). A phenomenological study of self-initiated expatriate adjustment (Order No. 10044089). Available from ProQuest Central;
ProQuest Dissertations \& Theses Global. (1776177247). https://search-proquestcom.eres.qnl.qa/docview/1776177247?accountid=4993

[65]. Burkhart, J. (2019). Employee Satisfaction with and Impact on Motivation of Forced Distribution Rating Systems (Order No. 27669725). Available from ProQuest Dissertations \& Theses Global. (2355993278). https://search-proquestcom.eres.qnl.qa/docview/2355993278?accountid=4993 6

[66]. Ndungu, D. N. (2017). The Effects of rewards and recognition on employee performance in public educational institutions: A Case of Kenyatta University, Kenya. Global Journal of Management and Business Research: A Administration and Management, $17(1), \quad 42-68$. https://globaljournals.org/GJMBR_Volume17/6-TheEffects-of-Rewards-and-Recognition.pdf

[67]. Sahito, Z., \&Vaisanen, P. (2019). A Narrative Analysis of Teacher Educators' Motivation: Evidence from the Universities of Sindh, Pakistan. Journal of Language Teaching and Research, 10(4), 673-682. http://dx.doi.org.eres.qnl.qa/10.17507/jltr.1004.02

[68]. Choi, Y., \& Ha, J. (2018). Job Satisfaction And Work Productivity: The Role Of Conflict-Management Culture. Social Behavior and Personality, 46(7), 11011110. http://dx.doi.org.eres.qnl.qa/10.2224/sbp.6940

[69]. Bartels, A. L., Peterson, S. J., \& Reina, C. S. (2019). Understanding well-being at work: Development and validation of the eudaimonic workplace well-being scale.PLoS One, 14(4) http://dx.doi.org.eres.qnl.qa/10.1371/journal.pone.0215 957

[70]. Novio, E. B. C. Tourist to Ajarn: The Filipino Teachers in Thailand.

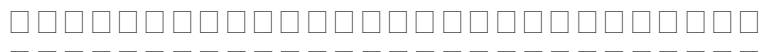

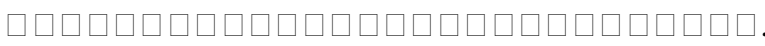
http://journalgrad.ssru.ac.th/index.php/8thconference/a rticle/view/1216.

[71]. Yi, S., Wu, N., Xiang, X., \& Liu, L. (2020, January 23). Challenges, Coping and Resources: A Thematic Analysis of Foreign Teachers' Experience of Cultural Adaptation in China. https://www.frontiersin.org/articles/10.3389/fpsyg.202 $0.00168 /$ full?utm_source=S-TWT.

[72]. wech, H., \&Gökçe, A. T. (2020, March 31). Challenges and Advantages of Working Abroad: Turkish and Turkish Culture Teachers' Perspective. International Journal of Psycho-Educational Sciences. https://eric.ed.gov/?id=EJ1250661.

[73]. Berg, A. T. (2019, May). The Experiences of Four Filipino Teachers in Obtaining Teaching Positions in Arizona: A Narrative Inquiry. ProQuest. https://search.proquest.com/openview/60e42ab358cba dd6c2024f070abd5ee5/1?pqorigsite $=$ gscholar $\& \mathrm{cbl}=18750 \&$ diss $=y$.

[74]. Cuenco, E. M. V. (2019). Finding Balance Between Filipino Cultural Identity and Early Childhood Teaching Practices. ProQuest. https://search-proquestcom.eres.qnl.qa/docview/2234780119/A14D14AAD7 AB4DA0PQ/1?accountid=49936. 
[75]. Gilman, K. P. (2016, November 21). Teacher Identity, Motivation, and Career in the EFL Setting. DigitalCommons@Hamline.

https://digitalcommons.hamline.edu/hse_all/4224/.

[76]. Wright, C. Y., \&Villaflor, P. C. C. (2019, February). Diasporic Queer in Classroom: The Resiliency of Filipino Gay Teachers in International Schools. https://www.researchgate.net/publication/332672657_ Diasporic_Queer_in_Classroom_The_Resiliency_of_F ilipino_Gay_Teachers_in_International_Schools.

[77]. Magulod, G. C. (2017, February). Personal Epistemologies and Teaching Styles of Filipino Preservice Elementary Teachers: Implications to Teacher Education Preparation Program. https://www.academia.edu/41971398/Personal_Episte mologies_and_Teaching_Styles_of_Filipino_Preservic e_Elementary_Teachers_Implications_to_Teacher_Ed ucation_Preparation_Program.

[78]. Correia, K., \& Marques-Pinto, A. (2016, July 11). Adaptation in the transition to school: perspectives of parents, preschool and primary school teachers. Taylor $\&$

Francis. https://www.tandfonline.com/doi/abs/10.1080/001318 81.2016.1200255.

[79]. S. Redillas, "Filipino Teachers' Identity: Framed by Community Engagements, Challenges for Citizenship Education," in The Palgrave Handbook of Citizenship and Education, A. Peterson, G. Stahl, and H. Soong, Eds. Cham: Springer International Publishing, 2020, pp. 275-295.

[80]. Shumenko, M. A., \&Kamalov, A. V. (2016). Ethnic migrant's adaptation problem to the recipient culture. НаучныйальманахстранПричерноморья, (1), 34-40.

[81]. Setti, I., Sommovigo, V., \&Argentero, P. (2020). Enhancing expatriates' assignments success: the relationships between cultural intelligence, crosscultural adaptation and performance. Current Psychology. doi:10.1007/s12144-020-00931-w

[82]. Wang, C. H., \& Varma, A. (2019). Cultural distance and expatriate failure rates: The moderating role of expatriate management practices. The International Journal of Human Resource Management, 30(15), 2211-2230.

[83]. Kim, Y. Y. (2017). Cross-Cultural Adaptation. Oxford Research Encyclopedia of Communication. doi:10.1093/acrefore/9780190228613.013.21

[84]. Watanabe, A. (2019). Asian Migrant Workers in the Arab Gulf States: The Growing Foreign Population and Their Lives. In 1020906815784375740 M. Ishii, 1020906816784375740 N. Hosoda, 1020906817 784375740 M. Matsuo, \& 1020906818784375740 K. Horinuki (Eds.), Asian migrant workers in the Arab Gulf States: The growing foreign population and their lives (pp. 194-214). Leiden: Brill. doi: https://doi.org/10.1163/9789004395404_012

[85]. Makhmudov, K. (2020). Ways of Forming Intercultural Communication in Foreign Language Teaching. doi: 10.6084/m9.figshare.12750647.v1

[86]. S. Maden, Attitudes of Foreigners Who Learn Turkish as a Second Language towards Turkish Culture, vol. 8. 2017.
[87]. Strachan, S. L. (2020). The Importance of Examining Cross-Cultural Issues Experienced by Foreign Science Teachers in U.S. Science Classrooms. Zenodo. doi: 10.5281/zenodo.4005957http://dx.doi.org.eres.qnl.qa/1 $0.17507 /$ jltr.1002.06

[88]. Lai, D. W., L., Shankar, J., \&Khalema, E. (2017) Unspoken Skills and Tactics: Essentials for Immigrant Professionals in Integration to Workplace Culture. Journal of International Migration and Integration, 18(3), 937-959. http://dx.doi.org.eres.qnl.qa/10.1007/s12134-0170513-5

[89]. Vallesteros, F. D. J. A., Dipasupil, P. A. E. B., Gamayon, R. A. V., Bautista, D. G. M., De Guzman, J. N. F., \& Milan, E. M. (2019). Leaving the Daylight: The Adjustments of Filipino Night Shift Workers in the State of Qatar. International Journal of Science and Research (IJSR), 8(11), 1739-1754.

[90]. Bogos, K. R. (2017). Space and Subversion: Precarious Labor and Migrant Worker Resistance in Qatar (Order No. 10273254). Available from ProQuest Dissertations \& Theses Global. (1903615703). https://search-proquest-

com.eres.qnl.qa/docview/1903615703 accountid=4993 6

[91]. Tuccio, M. (2017). Determinants of Intra-ASEAN Migration. Asian Development Review, 34(1), 144$166 . \quad$ https://search-proquestcom.eres.qnl.qa/docview/1881687827?accountid=4993 6

[92]. Claver, V. D. (2020, July 7). Career Satisfaction of Filipino Professional Self-Initiated Expatriates in Thailand. Asia Pacific Journal of Religions and Cultures. thaijo.org/index.php/ajrc/article/view/240094.

[93]. Tabuga, O. P. (2020). Phenomenological Study of Filipino Immigrant Teachers in South Texas. The Qualitative Report, 25(8), 3149-3162. https://searchproquest-

com.eres.qnl.qa/docview/2443868474?accountid=4993 6

[94]. Janiczak-Serafico, Z. (2020). Toward Financial Inclusion and Female Empowerment through Microfinance Development Initiatives in Manila and Central Luzon, Philippines (Order No. 27957635). Available from ProQuest Dissertations \& Theses Global. (2420686287). https://search-proquestcom.eres.qnl.qa/docview/2420686287?accountid=4993 6

[95]. Garcia, A. (2018). Parental Involvement Among LowIncome Filipinos: A Phenomenological Inquiry (Order No. 10791684). Available from ProQuest Central; ProQuest Dissertations \& Theses Global; Social Science Premium Collection. (2036840632). https://search-proquest-

com.eres.qnl.qa/docview/2036840632? accountid=4993 6

[96]. Bautista, A. G. M., \& Tamayo, V. T. (2020, October). Life Challenges of Overseas Filipino Workers. Open Access Library Journal. 
https://www.scirp.org/journal/paperinformation.aspx?p aperid $=103483$.

[97]. Acosta, A. S., Narisma, J. E. B., Belarmino, C. G. A., Maragana, T. M. P., Carino, R. M. U., \& Torres, M. K. D. (2020, January). Doing Things Right: The Lived Experience of Overseas Filipino Workers Having Brain Drain: Semantic Scholar. https://www.semanticscholar.org/paper/Doing-ThingsRight:-The-Lived-Experience-of-Workers-AcostaNarisma/37ddaa9d4fdbff9a26d40e9002c12a03299f703 2.

[98]. Tabuga, A. D. (2018, February). A probe into the Filipino migration culture: What is there to learn for policy intervention?EconStor. https://www.econstor.eu/handle/10419/211022.

[99]. Mariano, L. J. Z. (2017). Doing Good in Filipino Diaspora: Philanthropy, Remittances, and Homeland Returns. Journal of Asian American Studies, 20(2), 219-244. http://dx.doi.org.eres.qnl.qa/10.1353/jaas.2017.0017

[100]. Bongco, R. T., \& David, A. P. (2020). Filipino teachers' experiences as curriculum policy implementers in the evolving $\mathrm{K}$ to 12 landscape. Issues in Educational Research, 30(1), 19-34. https://searchproquestcom.eres.qnl.qa/docview/2391967727?accountid=4993 6

[101]. Baby Jane Uytico, Mark N. Abadiano (2020) Teachers' Tales: In-depth Exploration on Experiences of Millennial Filipino Teachers Abroad . Journal of Critical Reviews, 7 (17), 19521960. doi:10.31838/jcr.07.17.242

[102]. Brunton, M., \& Cook, C. (2018). Dis/Integrating cultural difference in practice and communication: A qualitative study of host and migrant Registered Nurse perspectives from New Zealand. International Journal of Nursing Studies, 83, 18-24. doi: 10.1016/j.ijnurstu.2018.04.005

[103]. Gül, H., \&Gökçe, A. T. (2020, March 31). Challenges and Advantages of Working Abroad: Turkish and Turkish Culture Teachers' Perspective. International Journal of Psycho-Educational Sciences. 